\title{
Escalonamento em Sistemas de Produção: um estudo de caso
}

\author{
EdÉsio RAImundo Sibrão
}

DisSERTAÇÃo APRESENTADA AO

Instituto DE MATEMÁtica E Estatística DA

Universidade de São Paulo para obtenção

do Grau de Mestre em Matemática Aplicada

Área de Concentração: CiÊnCIA DA ComputaÇÃO Orientador: Prof. Dr. Carlos Eduardo Ferreira

Durante a elaboração deste trabalho o autor recebeu apoio financeiro da Capes

São Paulo, dezembro de 1999 


\section{Escalonamento em Sistemas de Produção: um estudo de caso}

Este exemplar corresponde à redação final devidamente corrigida $e$ defendida por Edésio Raimundo Sibrão e aprovada pela comissão julgadora.

São Paulo, 13 de dezembro de 1999.

Banca Examinadora:

- Prof. Dr. Carlos Eduardo Ferreira

- Prof. Dr. Tamio Shimizu

- Prof. Dr. Marcos Nereu Arenales 


\section{Agradecimentos}

Primeiramente eu gostaria de agradecer encarecidamente a todas aquelas pessoas (seria impossível citar todas) que durante o (longo) período de desenvolvimento deste trabalho contribuiram de alguma forma, seja ela direta ou indireta, consciente ou não, para a sua execução.

Em especial gostaria de agradecer ao Carlinhos (Prof. Dr. Carlos Eduardo Ferreira) pela orientação dedicada, amizade, (muita) paciência, valiosas discussões, enfim, por ter me ajudado nesta realização.

Agradeço também à Cerâmica Atlas, em especial aos senhores Geraldo José Aloyse Ricciardi, José Roberto Bozzi e Wilson, que me proporcionaram todas as informações necessárias para este estudo de caso.

Ao professor Arenales e às professoras Yoshiko e Cristina agradeço pelas sugestões e comentários sobre o projeto.

À Capes deixo o meu agradecimento pela contribuição monetária durante grande parte do desenvolvimento deste trabalho.

E por fim, mas não menos importantes, agradeço a mais duas pessoas, os amigos sempre presentes, Edivar e Wanderlei. 


\section{Resumo}

Neste trabalho desenvolvemos uma ferramenta para otimizar a linha de produção de uma empresa que produz revestimentos cerâmicos. Este trabalho consiste de duas etapas. Na primeira parte realizamos uma introdução teórica sobre escalonamento e seqüenciamento, descrevendo alguns dos principais resultados da literatura tanto para uma máquina como para máquinas paralelas. Na segunda parte analisamos o processo produtivo da empresa, identificando os fatores relevantes ao processo, bem como entendendo toda a sua dinâmica. Uma vez identificado o problema, desenvolvemos uma solução para o mesmo utilizando como ponto de partida os resultados disponíveis na literatura.

O objetivo principal deste trabalho é o de exemplificar como funciona, na prática, o desenvolvimento da solução de um problema real, desde as visitas à empresa, para o desenvolvimento da formulação do problema e a busca dos dados experimentais, até a proposição da solução. 


\section{Abstract}

In this work we developed an optimizing tool for a ceramic facings line. The work is divided into two stages. First, we introduce the theoretical concepts of scheduling and sequencing, describing some of the main results in the literature for single and parallel machines. Second, we analyse the company's productive process, identifying its relevant factors and understanding its dynamics. Once the problem was identified we developed a solution using as a starting point the results on the literature.

The main goal of this work is to ilustrate the process of developing a solution for a real problem. Starting with the visits to the company we describe the process of formulation, the search for experimental data, finishing with the proposal of a solution. 


\section{Sumário}

I Introdução ao Escalonamento 10

1 Descrição dos problemas $\quad 13$

1.1 Definições iniciais . . . . . . . . . . . . . . . . . . . . . . 13

1.2 Características dos problemas . . . . . . . . . . . . 16

1.2.1 Características das máquinas: $\alpha \ldots \ldots \ldots . . \ldots 16$

1.2.2 Características das tarefas: $\beta \ldots \ldots \ldots 17$

1.2.3 Critério de otimalidade: $\gamma \ldots \ldots \ldots \ldots$

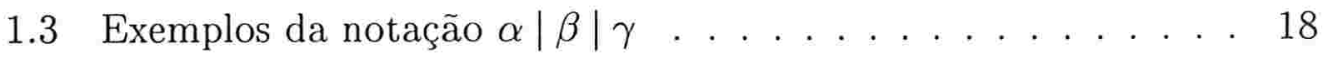

1.4 Reduções de problemas de escalonamento . . . . . . . . . . 18

2 Seqüenciamento de tarefas em uma máquina 21

2.1 Resultado Geral . . . . . . . . . . . . . . . . . . 21

2.2 Problemas sem tempos de conclusão . . . . . . . . . . . . . 22

2.2.1 Tempo de execução e estoque . . . . . . . . . . . 22

2.2.2 Minimização do tempo de execução médio . . . . . . . 23

2.2.3 Minimização do tempo de execução médio ponderado . 25

2.3 Problemas com tempos de conclusão . . . . . . . . . . . . 26

2.3.1 Critério de atraso . . . . . . . . . . . 26

2.3.2 Medidas de desempenho primária e secundária . . . . 29

2.3.3 Minimização do número de tarefas atrasadas . . . . . . 29

2.3.4 Minimização do atraso corrigido médio . . . . . . . . . 31

2.4 Chegadas não simultâneas . . . . . . . . . . . . . . . . . . 35

2.5 Tarefas dependentes . . . . . . . . . . . . . . . . . . 37

2.5.1 Generalização do seqüenciamento EDD . . . . . . . 37

2.6 Tempos de ajuste com dependência da seqüência . . . . . . . . 38

2.7 Principais resultados ... . . . . . . . . . . . . . 40 
3 Seqüenciamento de tarefas em máquinas paralelas 41

3.1 Máquinas paralelas idênticas e tarefas independentes . . . . . 41

3.1.1 Minimização do makespan . . . . . . . . . . . . . 41

3.1.2 Minimização do tempo de execução médio e do tempo de execução médio ponderado . . . . . . . . . . . . . 43

3.2 Máquinas paralelas idênticas e tarefas dependentes . . . . . . 46

3.3 Principais Resultados . . . . . . . . . . . . . . . . . . . . . . . 48

II Estudo de Caso $\quad 50$

4 Apresentação do problema $\quad 51$

4.1 Disposição da linha de produção . . . . . . . . . . . . . . . . 51

4.1.1 As prensas . . . . . . . . . . . . . . . . . . 53

4.1 .2 Os secadores . . . . . . . . . . . . . . . . . . . 54

4.1 .3 As esmaltadeiras . . . . . . . . . . . . . 55

4.1 .4 Os robôs . . . . . . . . . . . . . . . . 55

4.1 .5 Os pulmões . . . . . . . . . . . . . . . . . 55

4.1 .6 Os fornos . . . . . . . . . . . . . . . 56

4.2 Considerações sobre o sistema de produção . . . . . . . . . 56

4.3 Simplificação do problema . . . . . . . . . . . . . . 57

5 Modelagem $\quad 60$

5.1 Uma única máquina . . . . . . . . . . . . . . . . . . . 60

5.2 Formalização . . . . . . . . . . . . . . . . . . 61

5.3 Modelagem . . . . . . . . . . . . . . . . . . . . . . 62

5.4 Minimização do tempo de execução total . . . . . . . . . . . . 65

5.5 Minimização do número de tarefas atrasadas . . . . . . . . . . 66

5.6 Minimização do atraso total . . . . . . . . . . . . . . 68

6 Experimentos computacionais $\quad 70$

6.1 Coleta dos dados . . . . . . . . . . . . . . . . . 70

6.2 Simulações envolvendo PLI . . . . . . . . . . . . . . . . . . . . 74

6.3 Resolvendo o problema 1||$\sum T_{j} \ldots \ldots . \ldots . \ldots 75$

6.4 Resolvendo o problema $4 Q|| \sum T_{j} \ldots \ldots \ldots 78$ 


\section{Introdução}

Nos dias de hoje, temas como globalização, qualidade total e vantagem competitiva são continuamente debatidos pelos meios de comunicação e, principalmente, entre o meio empresarial. Com a abertura de mercado, o nível de concorrência tem aumentado despertando nas empresas o interesse pelo uso de ferramentas gerenciais que possam torná-las mais competitivas. No que se refere à gestão da produção, algumas ferramentas têm sido utilizadas para otimizar os processos produtivos objetivando melhorar a qualidade, bem como reduzir o custo e o tempo de fabricação. Em muitos casos essa busca por soluções chega até à comunidade científica, que procura aplicar seu conhecimento na resolução de problemas práticos.

Neste contexto, o objetivo deste trabalho é desenvolver uma ferramenta para otimizar uma linha de produção de uma empresa que produz revestimentos cerâmicos. O trabalho consiste basicamente de duas etapas. $\mathrm{Na}$ primeira etapa analisamos o processo produtivo de revestimento, através de visitas à empresa, procurando identificar os fatores relevantes ao processo, bem como entender toda a sua dinâmica. Na etapa seguinte fazemos a classificação do problema, ou seja, determinamos quais ferramentas matemáticas podem ser utilizadas para sua modelagem, objetivando melhores resultados.

Através deste projeto procuramos percorrer todas as etapas envolvidas na solução de um problema prático real: identificação do problema, desenvolvimento de um modelo matemático adequado e a aplicação das ferramentas desenvolvidas. Com isso esperamos poder contribuir para o estreitamento do intercâmbio entre as empresas e o meio acadêmico. Como objetivo principal do trabalho desejamos fornecer ao programador da produção uma ferramenta que poderá ser utilizada a fim de padronizar o processo produtivo da empresa. 


\section{Parte I}

\section{Introdução ao Escalonamento}




\section{Introdução}

Escalonamento é a alocação de recursos para a realização de uma coleção de tarefas durante um determinado intervalo de tempo. Essa definição geral nos conduz a dois significados distintos. Primeiro, escalonamento é uma ferramenta para tomada de decisão, ou seja, é o processo de determinação de uma programação. Segundo, escalonamento é uma teoria, isto é, é uma coleção de modelos, técnicas e conclusões lógicas que proporcionam a avaliação da programação.

A função do escalonamento somente se torna relevante numa situação onde a natureza das tarefas a serem escalonadas já tenha sido descrita e a configuração dos recursos disponíveis tenha sido determinada.

Podemos descrever os passos pelos quais as decisões de escalonamento são tomadas através de quatro estágios principais da abordagem de um sistema: formulação, análise, síntese e avaliação. No estágio da formulação, um problema é identificado e o critério que deverá guiar a tomada de decisões é determinado. Esta é freqüentemente uma atividade complicada, mas necessária, já que boas decisões raramente são encontradas sem uma definição clara do problema e dos objetivos. Análise é o processo detalhado de examinar os elementos de um problema e suas interrelações. É neste estágio que as variáveis de decisão são identificadas e também onde ocorre a especificação das relações entre as restrições que elas devem obedecer. Síntese é o processo de construir alternativas de soluções para o problema. Sua principal função é caracterizar as opções viáveis que estão disponíveis. Finalmente, avaliação é o processo de comparar estas alternativas viáveis e selecionar a ação a ser tomada. Esta seleção é, naturalmente, baseada nos critérios que foram escolhidos a priori.

Uma consideração precisa ser feita com respeito ao papel dos modelos em escalonamento. Podemos notar que os modelos são inerentes na abordagem dos sistemas e proporcionam uma base direta na tomada de decisões, quando 
a abordagem de sistemas é utilizada. Mesmo modelos muito simplificados também possuem o seu valor, sendo utilizados para representar a estrutura geral e as propriedades essenciais dos problemas de escalonamento.

Dois tipos de restrições de viabilidade são comumente encontradas em problemas de escalonamento. Primeiro, existem limites na capacidade dos recursos disponíveis. Segundo, existem restrições tecnológicas com relação à ordem na qual cada tarefa deve ser realizada. Uma solução de um problema de escalonamento é uma solução que respeita esses dois tipos de restrições. Com isso, resolver um problema de escalonamento significa responder a dois tipos de questões:

1. Quais recursos serão alocados para realizar cada tarefa?

2. Quando cada tarefa será realizada?

Em outras palavras, a essência dos problemas de escalonamento consiste em decisões de alocação e decisões de seqüenciamento. 


\section{Capítulo 1}

\section{Descrição dos problemas}

Neste capítulo introduziremos a notação dos problemas de escalonamento que será utilizada neste trabalho. Esta notação seguirá o mais próximo possível o esquema de classificação comumente encontrado na literatura [LLKS93].

\subsection{Definições iniciais}

Ao lidarmos com os atributos das tarefas em problemas de escalonamento é útil distinguirmos as informações que estão disponíveis a priori das informações que são geradas como resultado das decisões do escalonamento. As informações que nos ajudam a descrever as tarefas no caso determinístico são:

Tempo de chegada $\left(r_{j}\right)$ A posição no tempo na qual a tarefa $j$ está disponível para processamento (release time).

Tempo de início $\left(t_{j}\right)$ A posição no tempo na qual o processamento da tarefa $j$ inicia.

Tempo de processamento $\left(p_{j}\right)$ A quantidade de tempo requerida para o processamento da tarefa $j$ (processing time).

Tempo de conclusão $\left(d_{j}\right)$ A posição no tempo na qual o processamento da tarefa $j$ tem de estar concluído (due date).

As informações que são geradas como resultado das decisões do escalonamento representam a saída da função de escalonamento. Nos casos de- 
terminísticos, as decisões do escalonamento determinarão basicamente os seguintes fatores:

Tempo de finalização $\left(C_{j}\right)$ A posição no tempo na qual o processamento da tarefa $j$ está terminado (completion time).

Tempo de execução $\left(F_{j}\right)$ A quantidade de tempo que a tarefa $j$ permaneceu no sistema: $F_{j}=C_{j}-r_{j}$ (flowtime).

Atraso $\left(L_{j}\right)$ A quantidade de tempo que a finalização da tarefa $j$ excede seu tempo de conclusão: $L_{j}=C_{j}-d_{j}$ (lateness).

As duas últimas quantidades refletem dois tipos de serviço. O tempo de execução $F_{j}$ mede a resposta do sistema para demandas individuais de serviços e representa o intervalo que uma tarefa espera entre sua chegada no sistema e sua conclusão. Já o atraso $L_{j}$ mede a conformidade do escalonamento com relação aos tempos de conclusão, sendo importante notar que a quantidade $L_{j}$ possui valores negativos sempre que uma tarefa é terminada antes do seu tempo de conclusão. Por exemplo, se considerarmos a minimização dos tempos de finalização, valores negativos para o atraso $L_{j}$ representam um melhor serviço do que foi requisitado enquanto que valores positivos representam serviços piores. Se considerarmos alguma penalidade com relação ao atraso das tarefas, podemos definir a seguinte medida:

Penalidade unitária $\left(U_{j}\right)$

$$
U_{j}= \begin{cases}0 & \text { se } C_{j} \leq d_{j} \\ 1 & \text { caso contrário }\end{cases}
$$

Em muitas situações penalidades e outros custos serão associados a atrasos positivos, como na medida acima, mas nenhum benefício será associado a atrasos negativos. Dessa maneira é mais fácil trabalharmos com uma quantidade que mede somente atrasos positivos:

Atraso corrigido $\left(T_{j}\right)$ O atraso da tarefa $j$ se ela estiver atrasada, ou zero caso contrário: $T_{j}=\max \left\{0, L_{j}\right\}$ (tardiness).

Da mesma forma que podemos definir uma variável para medir o atraso corrigido, também podemos definir a seguinte medida: 
Adiantamento corrigido $\left(E_{j}\right) \mathrm{O}$ adiantamento da tarefa $j$ se ela estiver finalizada antes de seu tempo de conclusão, ou zero caso contrário: $E_{j}=\max \left\{0, d_{j}-C_{j}\right\}$ (earliness).

O adiantamento corrigido se torna uma medida importante, por exemplo, para os escalonamentos que envolvem esquemas de produção do tipo just in time.

Os escalonamentos são geralmente avaliados através de quantidades agregadas que envolvem informações sobre todas as tarefas. Por exemplo, suponha que $n$ tarefas devem ser escalonadas. As medidas agregadas de desempenho que podem ser definidas incluem as seguintes:

Tempo de execução médio

$$
\bar{F}=\frac{1}{n} \sum_{j=1}^{n} F_{j}
$$

Atraso corrigido médio

$$
\bar{T}=\frac{1}{n} \sum_{j=1}^{n} T_{j}
$$

Tempo de execução máximo

$$
F_{\max }=\max \left\{F_{j} \mid 1 \leq j \leq n\right\}
$$

Makespan

$$
C_{\max }=\max \left\{C_{j} \mid 1 \leq j \leq n\right\}
$$

Atraso corrigido máximo

$$
T_{\max }=\max \left\{T_{j} \mid 1 \leq j \leq n\right\}
$$

Número de tarefas atrasadas

$$
N_{T}=\sum_{j=1}^{n} \delta\left(T_{j}\right) ; \quad \delta(x)= \begin{cases}1 & \text { se } x>0 \\ 0 & \text { caso contrário }\end{cases}
$$




\subsection{Características dos problemas}

Um escalonamento é dito viável se não existir superposição em uma mesma máquina de intervalos de tempo alocados a diferentes tarefas, ou seja, cada máquina só pode executar uma tarefa por vez. Além disso, não há superposição dos intervalos de tempo de uma tarefa alocados a diferentes máquinas, isto é, cada tarefa só pode executar em uma máquina de cada vez. E ainda, o escalonamento deve obedecer a todas as características específicas do problema, tais como, tempo de conclusão, tempo de chegada, etc. Um escalonamento é ótimo se for viável e minimiza um certo critério de otimalidade.

$\mathrm{Na}$ seção anterior definimos vários tipos de quantidades e medidas associadas aos problemas de escalonamento. Entretanto, para definirmos unicamente um problema de escalonamento precisamos de outras informações. Por exemplo, precisamos saber o número de máquinas disponíveis, se as tarefas podem ser interrompidas durante a execução, se existe alguma prioridade entre essas tarefas, etc. Nesta seção apresentaremos uma notação para padronizar a descrição desses problemas.

Para facilitar o agrupamento dos diversos tipos de problemas de escalonamento, utilizamos uma classificação através de três parâmetros $\alpha|\beta| \gamma$, introduzida por Graham et al em [GLLK79]. O parâmetro $\alpha$ especifica as características das máquinas, $\beta$ as características das tarefas e $\gamma$ o critério de otimalidade do problema.

\subsubsection{Características das máquinas: $\alpha$}

O conjunto de máquinas é caracterizado por uma palavra de dois parâmetros $\alpha=\alpha_{1} \alpha_{2}$, onde $\alpha_{1} \in\{\circ, P, Q, R\}, \alpha_{2}$ é um inteiro positivo ou $\alpha_{2}=\circ$, que denota o símbolo de vazio.

Se $\alpha_{1}=$ o cada tarefa deve ser processada em uma máquina específica. Se $\alpha_{1}=P$, então existem máquinas paralelas idênticas, ou seja, para o tempo de processamento $p_{i j}$ da tarefa $i$ na máquina $j$, temos $p_{i j}=p_{i}$ para todas as máquinas $j$. Se $\alpha_{1}=Q$, existem máquinas paralelas uniformes, com $p_{i j}=p_{i} / s_{j}$, onde $s_{j}$ é a velocidade da máquina $j$. Finalmente, se $\alpha_{1}=R$, então as máquinas paralelas não são relacionadas, isto é, $p_{i j}=p_{i} / s_{i j}$, para velocidades $s_{i j}$ dependentes da máquina $j$ e da tarefa $i$.

Se $\alpha_{2}$ for igual a um inteiro positivo $1,2, \ldots$, então $\alpha_{2}$ denota o número de máquinas disponíveis. Se $\alpha_{2}=k$, então $k$ é um número arbitrário fixo de 
máquinas. Se o número de máquinas for arbitrário fazemos $\alpha_{2}=\circ$.

\subsubsection{Características das tarefas: $\beta$}

As características das tarefas são especificadas por um conjunto $\beta$ contendo no máximo cinco elementos: $\beta_{1}, \beta_{2}, \ldots, \beta_{5}$.

$\beta_{1}$ indica se interrupção é permitida. A interrupção de uma tarefa significa que o processamento pode ser interrompido e retomado em um instante posterior, até mesmo em uma outra máquina. Uma mesma tarefa pode ser interrompida várias vezes. Se a interrupção for permitida, fazemos $\beta_{1}=p m t n$ (preemption). Caso contrário $\beta_{1}$ não aparece em $\beta$.

$\beta_{2}$ descreve as relações de precedência entre as tarefas. Estas relações de precedência podem ser representadas, por exemplo, por grafos dirigidos. $\beta_{2}=$ prec se as relações de precedência forem um grafo dirigido acíclico arbitrário.

Se $\beta_{3}=r_{j}$ então o tempo de chegada deve ser especificado para cada tarefa. Se $r_{j}=0$ para todas as tarefas, então $\beta_{3}$ não aparece em $\beta$.

$\beta_{4}$ especifica as restrições sobre os tempos de processamento. Se $\beta_{4}$ é dado por $p_{j}=1$, então cada tarefa tem um tempo de processamento unitário.

Se $\beta_{5}=d_{j}$, então um tempo de conclusão $d_{j}$ é especificado para cada tarefa $j$, ou seja, a tarefa $j$ deve estar concluída até o instante $d_{j}$.

\subsubsection{Critério de otimalidade: $\gamma$}

Denotamos o tempo de finalização de uma tarefa $j$ por $C_{j}$ e o custo associado por $f_{j}\left(C_{j}\right)$. Como critério de otimalidade existem essencialmente dois tipos de funções custo total:

$$
\begin{gathered}
f_{\max }(C)=\max \left\{f_{j}\left(C_{j}\right) \mid 1 \leq j \leq n\right\} \mathrm{e} \\
\sum f_{j}(C)=\sum_{j=1}^{n} f_{j}\left(C_{j}\right) .
\end{gathered}
$$

Em geral, quando não são especificadas funções custos utilizamos $f(C)=$ $C$ e portanto o problema se resume a determinar a última tarefa a ser completada ou a soma dos tempos de finalização das tarefas. Entretanto, na maioria dos casos consideramos funções específicas $f_{j}$.

Outro fato a ser notado é que se existe algum esquema de prioridade entre as tarefas, podemos formalizá-lo na função objetivo através da atribuição de um peso $w_{j}$ para cada tarefa $j$ a ser escalonada. 


\subsection{Exemplos da notação $\alpha|\beta| \gamma$}

A fim de ilustrarmos a utilização da notação $\alpha|\beta| \gamma$ para problemas de escalonamento, daremos alguns exemplos. Iniciaremos com um dos problemas mais simples em escalonamento: $1\left|d_{j}\right| C_{\max }$. Ou seja, o problema de minimizar o makespan de um conjunto de tarefas que serão executadas em uma única máquina.

Já o problema $1\left|r_{j}, d_{j}\right| C_{\max }$ é idêntico ao anterior, com a diferença de que as tarefas também possuem tempo de chegada $r_{j}$. Esse mesmo problema com um número qualquer de máquinas paralelas idênticas é denotado por $P\left|r_{j}, d_{j}\right| C_{\max }$, enquanto que se existirem apenas duas máquinas paralelas não relacionadas será $2 R\left|r_{j}, d_{j}\right| C_{\max }$.

O problema $P \mid$ prec, $p_{j}=1 \mid C_{\max }$ consiste em escalonar tarefas com tempos de processamento unitários e restrições de precedência arbitrárias em $m$ máquinas paralelas tal que o makespan deve ser minimizado. Da mesma forma, $1\left|p m t n, r_{j}\right| L_{\max }$ é o problema de encontrar um escalonamento com interrupção permitida, em uma única máquina para um conjunto de tarefas com tempo de chegada tal que o atraso máximo seja minimizado.

Como podemos observar pelos exemplos acima, a notação $\alpha|\beta| \gamma$ simplifica a descrição dos problemas de escalonamento. Como exemplo final para ilustrar esse fato, vamos considerar o seguinte problema:

$$
3 R \mid p m t n, \text { prec }, r_{j}, p_{j}=1, d_{j} \mid T_{\max } .
$$

Esse problema consiste do escalonamento de $n$ tarefas com tempos de chegada e conclusão arbitrários e tempos de processamento unitários, com a interrupção de tarefas permitida e a existência de precedência entre elas, sendo que se deve minimizar o atraso corrigido máximo do escalonamento utilizando três máquinas não relacionadas.

\subsection{Reduções de problemas de escalonamen- to}

Quando tratamos de problemas de escalonamento podemos utilizar algumas transformações envolvendo as funções objetivo a fim de conseguirmos estudálos tendo como referência resultados já existentes na literatura. Por exemplo, a função objetivo $\sum f_{j}$ se reduz a $\sum w_{j} f_{j}$ fazendo $w_{j}=1$ para todo $j$. Ou 
seja, esta transformação não altera a característica do problema. Com isto conseguimos estender os resultados de um problema para o outro.

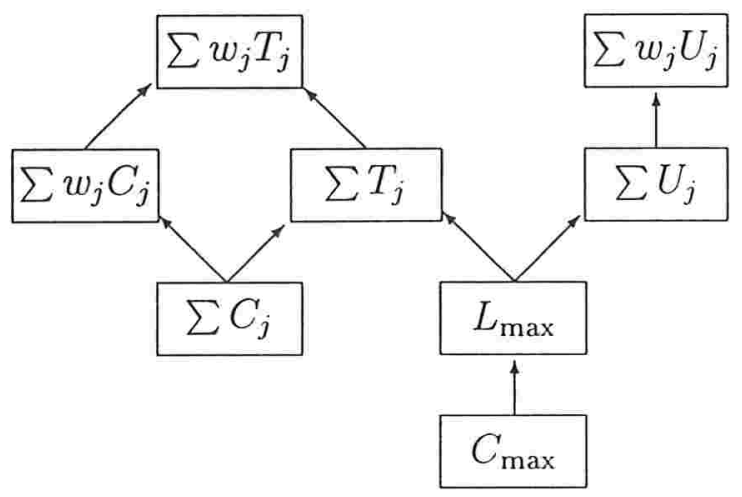

Figura 1.1: Redução de funções objetivo.

Da mesma forma $C_{\max }, \sum C_{j}$ e $\sum w_{j} C_{j}$ se reduzem respectivamente a $L_{\max }, \sum T_{j}$ e $\sum w_{j} T_{j}$ fazendo $d_{j}=0, \forall j$. E ainda, $L_{\max }$ se reduz a $\sum T_{j}$ e $\sum U_{j}$, pois:

$$
\begin{aligned}
\max L_{j} \leq k & \Longleftrightarrow C_{j}-d_{j} \leq k, \forall j \\
& \Longleftrightarrow C_{j}-\left(d_{j}+k\right) \leq 0, \forall j \\
& \Longleftrightarrow \max \left\{0, C_{j}-\left(d_{j}+k\right)\right\} \leq 0, \forall j \\
& \Longleftrightarrow \sum T_{j}=\sum \max \left\{0, C_{j}-\left(d_{j}+k\right)\right\} \leq 0 \\
& \Longleftrightarrow \sum U_{j} \leq 0 .
\end{aligned}
$$

Na Figura 1.1 podemos observar essas reduções esquematicamente.

Analogamente às reduções das funções objetivo dos problemas de escalonamento, também podemos reduzir as restrições associadas. A Figura 1.2 apresenta um esquema dessas reduções. 


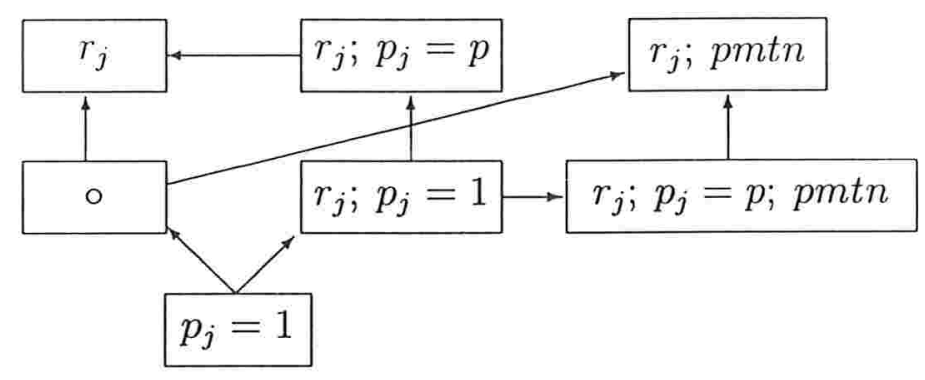

Figura 1.2: Redução de restrições. 


\section{Capítulo 2}

\section{Seqüenciamento de tarefas em uma máquina}

O problema de seqüenciamento é um problema de escalonamento especializado no qual a ordenação das tarefas determina completamente uma programação. O problema de seqüenciamento mais simples é aquele que possui uma única máquina. Mesmo sendo muito simples, o caso de uma única máquina é importante por várias razões. Por exemplo, no processo de aprendizado, o problema de uma única máquina é significante pois pode ilustrar uma variedade de tópicos de escalonamento num modelo tratável. Ele proporciona um contexto para a investigação de várias medidas de desempenho e também várias técnicas de solução. Ou seja, esse problema mais simples é a base para o entendimento dos conceitos de escalonamento, facilitando posteriormente o modelamento de sistemas mais complicados.

\subsection{Resultado Geral}

O caso com uma única máquina tem sido o objeto de uma extensiva pesquisa desde os trabalhos de Jackson [Jac55] e Smith [Smi56]. Neste capítulo apresentaremos algoritmos para esses problemas de escalonamento envolvendo uma única máquina. Iniciaremos nossa descrição através da apresentação de um resultado geral que vale para problemas de escalonamento envolvendo uma única máquina: 
Se todos os tempos de chegada forem zero e a função objetivo for uma função monotonicamente crescente ${ }^{1}$ dos tempos de conclusão das tarefas, então somente os escalonamentos sem interrupçâo $e$ sem tempo ocioso entre tarefas precisam ser considerados.

Este resultado segue do fato de que o valor objetivo ótimo não é melhorado se a interrupção de tarefas for permitida. Para vermos como isso ocorre, considere um escalonamento no qual alguma tarefa $j$ foi interrompida, ou seja,

- $j$ é escalonada em $\left[t_{1}, t_{2}\left[\right.\right.$ e $\left[t_{3}, t_{4}\left[\right.\right.$, onde $t_{1}<t_{2}<t_{3}<t_{4}$;

- $j$ não é escalonada em $\left[t_{2}, t_{3}\left[\right.\right.$ e nem antes de $t_{1}$.

Ao reescalonarmos a tarefa $j$ de forma que a parte de seu processamento em $\left[t_{1}, t_{2}\right.$ [ é escalonada entre $t_{3}-\left(t_{2}-t_{1}\right)$ e $t_{3}$, e tal que qualquer tarefa escalonada entre $t_{2}$ e $t_{3}$ é deslocada $t_{2}-t_{1}$ unidades de tempo para trás, nós eliminamos essa interrupção de $j$ sem aumentar a função objetivo. E ainda, nenhuma nova interrupção foi criada. Dando continuidade a esse processo, obtemos uma solução ótima para o problema com interrupção permitida, onde nenhuma interrupção é necessária. Note que essa transformação pode criar inviabilidade se $r_{j} \neq 0$ para alguma tarefa $j$.

\subsection{Problemas sem tempos de conclusão}

\subsubsection{Tempo de execução e estoque}

Algumas vezes os custos associados com as decisões de escalonamento envolvem serviços a clientes, que se refletem no tempo gasto no sistema. O objetivo do escalonamento nestes casos é terminar rapidamente o processamento. Em outras situações os custos envolvem investimentos nas disponibilidades do sistema, refletindo no comportamento dos estoques durante o processo. Para esses casos o objetivo do escalonamento é manter baixos os níveis de estoque. A relação íntima entre esses dois objetivos pode ser ilustrada através do modelo básico de uma única máquina.

\footnotetext{
${ }^{1}$ Consideramos uma função $f(x)$ monotonicamente crescente se $m \leq n$ implica em $f(m) \leq f(n)$.
} 
Considere $J(t)$ como sendo o número de tarefas no sistema no tempo $t$ e $\bar{J}$ o número médio de tarefas no sistema durante um determinado intervalo de tempo. Nestas condições, $\bar{J}$ satisfaz a seguinte relação:

$$
\bar{F} n=\bar{J} F_{\max },
$$

onde $\bar{F}$ e $F_{\max }$ são dadas pelas equações 1.1 e 1.3 respectivamente, e $n$ é o número de tarefas a serem escalonadas. Ou seja, uma vez que $n$ e $F_{\max }$ são ambas constantes dadas, $\bar{J}$ é diretamente proporcional a $\bar{F}$. Isso significa que a seqüência de tarefas que minimiza $\bar{F}$ (tempo de execução médio) também minimizará $\bar{J}$ (estoque médio durante o processo) ${ }^{2}$. Com isso, otimizar o serviço aos clientes ou minimizar o nível de estoque durante o processo recai no mesmo problema: encontrar a seqüência que minimiza $\bar{F}$. Essa relação entre tempo de execução e estoque também pode ser estendida para outros tipos de problemas envolvendo o seqüenciamento com uma única máquina. Por exemplo, esta relação pode ser estendida para o caso em que as tarefas possuem tempos de chegada [Max70].

\subsubsection{Minimização do tempo de execução médio}

Considere o gráfico $J(t) \times t$ e o problema de minimizar $\bar{F}$. Um problema equivalente é o de minimizar a área sob a curva $J(t)$. Note que essa área pode ser minimizada rearranjando as tarefas em ordem crescente dos tempos de processamento. Esse tipo de seqüenciamento é conhecido como menor tempo de processamento (SPT) por razões óbvias, mas também é conhecido por uma variedade de outros nomes, tais como menor tempo de operação e menor operação iminente. O Teorema 2.1 formaliza a otimalidade de SPT [Bak74].

Teorema 2.1 O tempo de execução médio $\bar{F}$ é minimizado pelo seqüenciamento SPT.

Prova Considere uma seqüência $S$ que não seja uma seqüência SPT. Ou seja, em alguma posição de $S$ deve existir um par de tarefas adjacentes $i$ e $j$, com $j$ seguindo $i$, tal que $p_{i}>p_{j}$. Construa uma nova seqüência $S^{\prime}$ na qual as tarefas $i$ e $j$ estão com as posições trocadas na seqüência e todas

\footnotetext{
${ }^{2} \mathrm{O}$ objetivo de manter baixo o nível de estoque pode ser interpretado como a minimização do número de tarefas que estão no sistema.
} 

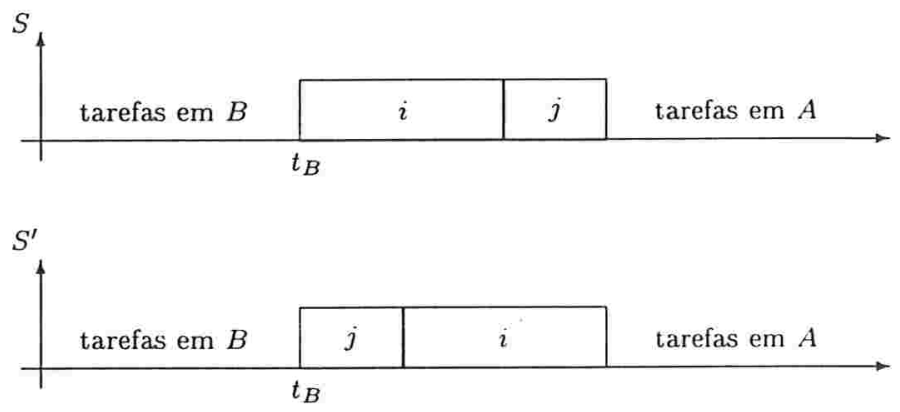

Figura 2.1: Seqüenciamentos $S$ e $S^{\prime}$.

as outras tarefas são finalizadas nos mesmos tempos da seqüência $S$. Na Figura 2.1 podemos observar estas duas seqüencias, onde $t_{B}$ denota o instante de tempo no qual a tarefa $i$ inicia em $S$ e no qual a tarefa $j$ inicia em $S^{\prime}$. $B$ denota o conjunto de tarefas que precedem as tarefas $i$ e $j$ nas duas seqüências e, analogamente, $A$ denota o conjunto de tarefas que seguem $i$ e $j$.

Denotaremos $F_{k}(S)$ como sendo o tempo de execução da tarefa $k$ no escalonamento $S$. Para o nosso resultado é suficiente que consideremos como critério $\sum_{k=1}^{n} F_{k}$, uma vez que este difere de $\bar{F}$ somente por uma constante. Primeiramente mostraremos que $\sum_{k=1}^{n} F_{k}$ é menor em $S^{\prime}$ do que em $S$ :

$$
\begin{aligned}
\sum_{k=1}^{n} F_{k}(S) & =\sum_{k \in B} F_{k}(S)+F_{i}(S)+F_{j}(S)+\sum_{k \in A} F_{k}(S) \\
& =\sum_{k \in B} F_{k}(S)+\left(t_{B}+p_{i}\right)+\left(t_{B}+p_{i}+p_{j}\right)+\sum_{k \in A} F_{k}(S) ; \\
\sum_{k=1}^{n} F_{k}\left(S^{\prime}\right) & =\sum_{k \in B} F_{k}\left(S^{\prime}\right)+\left(t_{B}+p_{j}\right)+\left(t_{B}+p_{j}+p_{i}\right)+\sum_{k \in A} F_{k}\left(S^{\prime}\right) .
\end{aligned}
$$

Desta forma

$$
\sum_{k=1}^{n} F_{k}(S)-\sum_{k=1}^{n} F_{k}\left(S^{\prime}\right)=p_{i}-p_{j}>0
$$

Ou seja, a troca das tarefas $i$ e $j$ reduz o valor de $\bar{F}$. Conseqüentemente qualquer seqüência que não seja uma seqüência SPT pode ser melhorada através de uma troca de pares adjacentes de tarefas. Disto segue que o seqüenciamento SPT é ótimo. 
Associado ao Teorema 2.1 existem algumas propriedades. Primeira, devido à relação entre tempo de execução e estoque, o seqüenciamento SPT além de minimizar $\bar{F}$ também minimiza $\bar{J}$. Segunda, se o tempo de espera da tarefa $j$ é definido como sendo o tempo gasto no sistema pela tarefa $j$ desde o instante em que ela está disponível no sistema até o início de seu processamento, então pode ser mostrado que o seqüenciamento SPT minimiza o tempo de espera médio (Teorema 2.2).

Teorema 2.2 O tempo de espera médio é minimizado pelo seqüenciamento SPT.

Prova Seja $S$ um escalonamento obtido por SPT e tome o escalonamento $S^{\prime}$ ótimo para o tempo de espera médio. Mas observe que

$$
\sum_{j \in S} F_{j}=\sum_{j \in S}\left(C_{j}-t_{j}\right)+\sum_{j \in S}\left(t_{j}-r_{j}\right)=\sum_{j \in S} p_{j}+\sum_{j \in S}\left(t_{j}-r_{j}\right) .
$$

Da mesma forma,

$$
\sum_{j \in S^{\prime}} F_{j}=\sum_{j \in S^{\prime}} p_{j}+\sum_{j \in S^{\prime}}\left(t_{j}-r_{j}\right) .
$$

Como $S$ é ótimo para $\bar{F}$ e $\sum_{j \in S} F_{j}=\sum_{j \in S^{\prime}} F_{j}$ temos que

$$
0<\sum_{j \in S^{\prime}} F_{j}-\sum_{j \in S} F_{j}=\sum_{j \in S^{\prime}}\left(t_{j}-r_{j}\right)-\sum_{j \in S}\left(t_{j}-r_{j}\right)
$$

contrariando a hipótese de que $S^{\prime}$ é ótimo com relação ao tempo de espera médio. Portanto, SPT também minimiza o tempo de espera médio.

\subsubsection{Minimização do tempo de execução médio pon- derado}

O problema de minimizar o tempo de execução médio ponderado é uma variação do problema de minimizar $\bar{F}$. Neste tipo de problema as tarefas não possuem a mesma importância. Uma maneira de modelar essa característica é atribuir fatores de peso $w_{j}$ a cada tarefa e incorporar esses fatores de peso nas medidas de desempenho. A versão ponderada do tempo de execução médio é definida por

$$
\bar{F}_{w}=\frac{\sum_{j=1}^{n} w_{j} F_{j}}{\sum_{j=1}^{n} w_{j}}
$$


onde o denominador é somente uma constante de normalização.

Todos os resultados anteriores podem ser estendidos para a versão ponderada, cuja generalização é resumida através do Teorema 2.3.

Teorema 2.3 O tempo de execução médio ponderado $\bar{F}_{w}$ é minimizado pelo seqüenciamento WSPT (menor tempo de processamento ponderado).

Prova A prova utilizando a troca de pares de tarefas adjacentes é análoga àquela do Teorema 2.1.

\subsection{Problemas com tempos de conclusão}

\subsubsection{Critério de atraso}

Como vimos anteriormente, o atraso de uma tarefa $j$ é definido como $L_{j}=$ $C_{j}-d_{j}$, ou seja, a diferença entre os tempos de finalização e conclusão. Um resultado interessante é que o atraso médio mínimo é encontrado pelo seqüenciamento SPT. Este resultado é interessante pois uma regra de seqüenciamento que ignora as informações sobre tempos de conclusão é ótima para um critério orientado para tempos de conclusão (Teorema 2.4).

Teorema 2.4 O atraso médio $\bar{L}$ é minimizado pelo seqüenciamento SPT.

Prova Por definição temos:

$$
\begin{aligned}
\bar{L} & =\frac{1}{n} \sum_{j=1}^{n} L_{j}=\frac{1}{n} \sum_{j=1}^{n}\left(C_{j}-d_{j}\right)=\frac{1}{n} \sum_{j=1}^{n}\left(F_{j}-d_{j}\right) \\
& =\frac{1}{n} \sum_{j=1}^{n} F_{j}-\frac{1}{n} \sum_{j=1}^{n} d_{j}=\bar{F}-\bar{d}
\end{aligned}
$$

onde $\bar{d}$ é a média dos tempos de conclusão do conjunto de tarefas e conseqüentemente é uma constante. $\mathrm{Na}$ equação acima consideramos $C_{j}=F_{j}$ pois $r_{j}=0, \forall j$. Desta forma, como $\bar{L}$ difere de $\bar{F}$ por uma constante que é independente da seqüência, a seqüência que minimiza $\bar{L}$ será a seqüência que minimiza $\bar{F}$. Pelo Teorema 2.1 esta é a seqüência SPT. 
Uma abordagem intuitiva para um seqüenciamento que obedeça os tempos de conclusão é o seqüenciamento das tarefas de acordo com alguma medida de urgência do tempo de conclusão. Utilizando o seqüenciamento pelo tempo de conclusão mais próximo (EDD) não garantimos que $\bar{L}$ será minimizado (o seqüenciamento SPT garante isso). O que pode ser mostrado é que o seqüenciamento EDD minimiza o atraso máximo do escalonamento. Para ilustrar esse fato, considere o exemplo com quatro tarefas da Tabela 2.1. Na Tabela 2.2 podemos observar que a seqüência obtida por SPT gerou um atraso médio $\bar{F}$ menor do que aquele gerado por EDD (Teorema 2.4). Para o caso do atraso máximo $L_{\max }$ o resultado foi o inverso (Teorema 2.5).

\begin{tabular}{ccc} 
Tarefa $j$ & $p_{j}$ & $d_{j}$ \\
\hline 1 & 3 & 7 \\
2 & 4 & 6 \\
3 & 2 & 3 \\
4 & 1 & 5
\end{tabular}

Tabela 2.1: Exemplo para comparação entre SPT e EDD.

\begin{tabular}{cccc}
\hline & Seqüenciamento & $\bar{L}$ & $L_{\max }$ \\
\hline Algoritmo & ótimo & $-1 / 4$ & 4 \\
SPT & $4-3-1-2$ & $1 / 4$ & 3 \\
EDD & $3-4-2-1$ & $1 / 4$ \\
\hline
\end{tabular}

Tabela 2.2: Comparação dos escalonamentos SPT e EDD.

\section{Algoritmo 2.1 - Seqüenciamento $\mathrm{EDD}^{3}$}

Passo 1 Comece com uma seqüência arbitrária não EDD;

Passo 2 Localize um par de tarefas adjacentes $i j$, com $j$ seguindo $i$, tal que $d_{i}>d_{j}$;

Passo 3 Troque as tarefas $i$ e $j$;

\footnotetext{
${ }^{3}$ Como está descrito, esse algoritmo é um Bubble Sort. Entretanto, podemos implementá-lo ordenando as tarefas em ordem crescente dos $d_{j}$ através do algoritmo Quick Sort, em $O(n \log n)$
} 
Passo 4 Retorne ao Passo 2 iterativamente até que uma seqüência EDD seja construída.

Teorema 2.5 O atraso máximo $L_{\max }$ e o atraso corrigido máximo $T_{\max }$ são minimizados pelo seqüenciamento EDD.

Prova Utilizaremos novamente o método da troca de pares de tarefas adjacentes (Figura 2.1). Considere uma seqüência $S$ que não seja uma seqüência EDD. Isto é, em alguma posição de $S$ deve existir um par de tarefas adjacentes $i$ e $j$, com $j$ seguindo $i$, tal que $d_{i}>d_{j}$. Agora construa uma nova seqüência $S^{\prime}$ na qual as tarefas $i$ e $j$ estão com as posições trocadas e todas as outras tarefas são finalizadas nos mesmos tempos da seqüência $S$. Assim:

$$
\begin{array}{ll}
L_{i}(S)=t_{B}+p_{i}-d_{i} & L_{j}\left(S^{\prime}\right)=t_{B}+p_{j}-d_{j} \\
L_{j}(S)=t_{B}+p_{i}+p_{j}-d_{j} & L_{i}\left(S^{\prime}\right)=t_{B}+p_{j}+p_{i}-d_{i}
\end{array}
$$

no que segue que $L_{j}(S)>L_{i}\left(S^{\prime}\right)$ e $L_{j}(S)>L_{j}\left(S^{\prime}\right)$. Então

$$
L_{j}(S)>\max \left\{L_{i}\left(S^{\prime}\right), L_{j}\left(S^{\prime}\right)\right\} .
$$

Seja $L=\max \left\{L_{k} \mid k \in A\right.$ ou $\left.k \in B\right\}$, com A e B definidos como na Figura 2.1, e note que $L$ é o mesmo tanto em $S$ como em $S^{\prime}$. Desta forma

$$
L_{\max }(S)=\max \left\{L, L_{i}(S), L_{j}(S)\right\} \geq \max \left\{L, L_{i}\left(S^{\prime}\right), L_{j}\left(S^{\prime}\right)\right\}=L_{\max }\left(S^{\prime}\right) .
$$

Em outras palavras, a troca das tarefas $i$ e $j$ não aumenta o valor de $L_{\text {max }}$, podendo reduzi-lo, isto é, melhorá-lo. Portanto, uma seqüência ótima pode ser construída através do seqüenciamento EDD.

Da mesma forma podemos provar que o seqüenciamento EDD também minimiza $T_{\max }$, começando com a equação

$$
T_{\max }(S)=\max \left\{0, L_{\max }(S)\right\} \geq \max \left\{0, L_{\max }\left(S^{\prime}\right)\right\}=T_{\max }\left(S^{\prime}\right) .
$$




\subsubsection{Medidas de desempenho primária e secundária}

Uma variação importante para o problema com um único critério envolve a designação de medidas de desempenho primária e secundária. A medida primária é o critério dominante, mas se existem soluções alternativas ótimas com respeito à medida primária, então devemos escolher a melhor seqüência entre essas alternativas com respeito à medida secundária.

Por exemplo, suponha que alguma medida baseada no atraso corrigido (tal como $\bar{T}$ ) seja a medida primária e que existam várias seqüências que são consideradas "perfeitas" porque não contêm tarefas atrasadas. E ainda, suponha que $\bar{F}$ seja a medida secundária. Assim, para construirmos uma seqüência perfeita que minimize $\bar{F}$ podemos empregar a Regra de Smith [Smi56]:

A tarefa $j$ deve ser colocada na última posição da seqüência somente se:

1. $d_{j} \geq \sum_{k=1}^{n} p_{k},{ }^{4}$

2. $p_{j} \geq p_{i}$ entre todas as tarefas $i$ tais que $d_{i} \geq \sum_{k=1}^{n} p_{k}$.

De acordo com a regra acima, se alguma outra tarefa deve ir para a última posição da seqüência, então uma melhora óbvia pode ser obtida colocando-se a tarefa $j$ na última posição da seqüência. Uma vez que a Regra de Smith tenha identificado a última tarefa entre $n$, restam $(n-1)$ tarefas para as quais a regra pode ser novamente aplicada. Se continuarmos aplicando a regra, construiremos uma seqüência ótima que tem como medida de desempenho primária $\bar{T}$ e medida de desempenho secundária $\bar{F}$. Na Tabela 2.3 temos um exemplo com cinco tarefas ilustrativo deste caso, com todos os passos da Regra de Smith até a obtenção da seqüência ótima descritos na Tabela 2.4 .

\subsubsection{Minimização do número de tarefas atrasadas}

Se uma determinada seqüência EDD não possuir nenhuma tarefa atrasada então ela é ótima com relação ao número de tarefas atrasadas $N_{T}$. Entretanto, se essa seqüência possuir tarefas atrasadas então pode ser que ela não seja ótima com relação a $N_{T}$. O Algoritmo 2.2 [Moo68] é um algoritmo eficiente que resolve o caso geral. Seu método de resolução assume que a forma de uma seqüência ótima é a seguinte:

\footnotetext{
${ }^{4}$ Sempre existirá uma tarefa $j$ que satisfaz a Condiçāo (1) pois, pela hipótese do problema, nas seqüências consideradas não existe nenhuma tarefa atrasada.
} 


\begin{tabular}{ccc} 
Tarefa $j$ & $p_{j}$ & $d_{j}$ \\
\hline 1 & 4 & 16 \\
2 & 7 & 16 \\
3 & 1 & 8 \\
4 & 6 & 21 \\
5 & 3 & 9
\end{tabular}

Tabela 2.3: Exemplo para a Regra de Smith.

\begin{tabular}{cccc}
\hline$\sum p_{j}$ & Condição 1 & Condição 2 & Seqüência \\
\hline 21 & 4 & 4 & 4 \\
15 & $1 ; 2$ & 2 & $2-4$ \\
8 & $1 ; 3 ; 5$ & 1 & $1-2-4$ \\
4 & $3 ; 5$ & 5 & $5-1-2-4$ \\
Seqüência ótima: $3-5-1-2-4$ & $(\bar{T}=0 ; \bar{F}=9.8)$ \\
\hline
\end{tabular}

Tabela 2.4: Aplicação da Regra de Smith.

1. Primeiro, um conjunto $E^{*}$ de tarefas "dentro do prazo" (não atrasadas), ordenadas pelo seqüenciamento EDD;

2. A seguir um conjunto $L^{*}$ de tarefas atrasadas, em qualquer ordem.

A suposição de que as tarefas "dentro do prazo" devem estar ordenadas por EDD não gera nenhuma restrição, pois se qualquer seqüência de tarefas não tem nenhum atraso, então podemos assegurar que a seqüência EDD para essas tarefas não terá nenhum atraso.

\section{Algoritmo 2.2 - Algoritmo de Hodgson para minimizar $N_{T}$}

Passo 1 Coloque todas as tarefas no conjunto $E$ utilizando o seqüenciamento $E D D$;

Passo 2 Se nenhuma tarefa em E estiver atrasada pare: E é ótima. Caso contrário, identifique a primeira tarefa atrasada em E. Suponha que seja a tarefa $j$.

Passo 3 Identifique a tarefa mais longa entre as $j$ primeiras tarefas na seqüencia. Remova essa tarefa de $E$ e a coloque em L. Recalcule os tempos de finalização das tarefas que restaram em E e retorne ao Passo 2. 
A prova da otimalidade do Algoritmo 2.2 pode ser encontrada em [Stu70].

\begin{tabular}{ccc} 
Tarefa $j$ & $p_{j}$ & $d_{j}$ \\
\hline 1 & 1 & 2 \\
2 & 5 & 7 \\
3 & 3 & 8 \\
4 & 9 & 13 \\
5 & 7 & 11
\end{tabular}

Tabela 2.5: Exemplo para o algoritmo de Hodgson.

Para ilustrarmos o Algoritmo de Hodgson considere o exemplo da Tabela 2.5. No Passo 1 as tarefas são ordenadas por EDD e a Tarefa 3 é a primeira tarefa atrasada: $E=\{1-2-3-5-4\}$ e $L=\emptyset$. A tarefa mais longa na seqüência até a Tarefa 3 e incluindo esta é a Tarefa 2 . Desta forma a Tarefa 2 é removida do conjunto $E$ e colocada no conjunto $L: E=\{1-3-5-4\}$ e $L=\{2\}$. No Passo 2, a Tarefa 4 é removida de $E$ e colocada em $L$ : $E=\{1-3-5\}$ e $L=\{2-4\}$, e no Passo 3 nenhuma tarefa atrasada resta em $E$. Desta forma o algoritmo determina duas seqüências ótimas $\left(N_{T}=2\right)$ : $1-3-5-2-4$ e $1-3-5-4-2$, uma vez que as tarefas atrasadas podem aparecer em qualquer ordem.

\subsubsection{Minimização do atraso corrigido médio}

As medidas de desempenho que visam à satisfação dos tempos de conclusão das tarefas são as mais utilizadas em problemas práticos. Entretanto, a dificuldade em lidar com o atraso corrigido médio e também com outras medidas de desempenho baseadas no critério de atraso corrigido reside no fato de que este não é uma função linear com relação ao tempo de finalização.

Apresentaremos nesta seção um algoritmo pseudopolinomial para o problema 1||$\sum T_{j}$ que é devido a Lawler [Law77] $]^{5}$ Este algoritmo também é aplicável ao problema 1||$\sum w_{j} T_{j}$ desde que os pesos $w_{j}$ possam ser agregados aos tempos de processamento $p_{j}$ (isto é, se $p_{i}<p_{j}$ implica $w_{i} \geq w_{j}$ para $j=1, \ldots, n)$, que assumimos serem números inteiros. Claramente os pesos $w_{j}=1$ são agregáveis. Esse algoritmo é baseado nos resultados que se seguem.

\footnotetext{
${ }^{5}$ Du e Leung provaram que este problema é $\mathcal{N} \mathcal{P}$-difícil [DL90].
} 
Lema 2.1 Considere as tarefas com pesos arbitrários. Seja $\pi$ qualquer seqüência que seja ótima com respeito aos tempos de conclusão $d_{1}, d_{2}, \ldots, d_{n}$, e seja $C_{j}$ o tempo de finalização da tarefa $j(j=1, \ldots, n)$ para esta seqüência. Escolha $d_{j}^{\prime}$ tal que $\min \left\{d_{j}, C_{j}\right\} \leq d_{j}^{\prime} \leq \max \left\{d_{j}, C_{j}\right\}$, para todo $j$. Então qualquer seqüencia $\pi^{\prime}$ que seja ótima com respeito aos tempos de conclusão $d_{1}^{\prime}, d_{2}^{\prime}, \ldots, d_{n}^{\prime}$ também será ótima com respeito a $d_{1}, d_{2}, \ldots, d_{n}$.

Prova Vamos denotar o atraso ponderado total com respeito a $d_{1}, d_{2}, \ldots, d_{n}$ por $T$ e $T^{\prime}$ o atraso ponderado total com respeito a $d_{1}^{\prime}, d_{2}^{\prime}, \ldots, d_{n}^{\prime}$. Seja $\pi^{\prime}$ qualquer seqüência que seja ótima com respeito a $d_{1}^{\prime}, d_{2}^{\prime}, \ldots, d_{n}^{\prime}$ e seja $C^{\prime}$ o tempo de finalização da tarefa $j$ para esta seqüência. Desta forma temos

$$
\begin{aligned}
T(\pi) & =T^{\prime}(\pi)+\sum_{j} A_{j} \\
T\left(\pi^{\prime}\right) & =T^{\prime}\left(\pi^{\prime}\right)+\sum_{j} B_{j}
\end{aligned}
$$

onde, se $C_{j} \leq d_{j}$ :

$$
\begin{aligned}
& A_{j}=0 \\
& B_{j}=-w_{j} \max \left\{0, \min \left\{C_{j}^{\prime}, d_{j}\right\}-d_{j}^{\prime}\right\}
\end{aligned}
$$

e se $C_{j} \geq d_{j}$

$$
\begin{aligned}
& A_{j}=w_{j}\left(d_{j}^{\prime}-d_{j}\right) \\
& B_{j}=w_{j} \max \left\{0, \min \left\{C_{j}^{\prime}, d_{j}^{\prime}\right\}-d_{j}\right\} .
\end{aligned}
$$

Podemos observar que $A_{j} \geq B_{j}$ e $\sum_{j} A_{j} \geq \sum_{j} B_{j}$. E ainda, $T^{\prime}(\pi) \geq$ $T^{\prime}\left(\pi^{\prime}\right)$, pois assumimos que $\pi^{\prime}$ minimiza $T^{\prime}$. Portanto o lado direito da Equação 2.3 domina o lado direito da Equação 2.4. Disto segue que $T(\pi) \geq T\left(\pi^{\prime}\right)$ é ótimo com respeito a $d_{1}^{\prime}, d_{2}^{\prime}, \ldots, d_{n}^{\prime}$.

Lema 2.2 Suponha que as tarefas estão com os pesos agregados. Então existe uma seqüencia ótima $\pi$ na qual a tarefa $i$ precede a tarefa $j$ se $d_{i} \leq d_{j}$ e $p_{i}<p_{j}$, e na qual todas as tarefas não atrasadas estão em ordem crescente de tempos de conclusão. 
Prova Seja $\pi$ uma seqüência ótima. Suponha que $j$ preceda $i$ em $\pi$, onde $d_{i} \leq d_{j}$ e $p_{i}<p_{j}$. Então uma simples troca de $i$ e $j$ gera uma seqüência para a qual o atraso ponderado total não aumenta (conforme [KLL75], Teorema 1). Se $j$ precede $i$, onde $d_{i} \leq d_{j}$ e $i$ e $j$ estão ambos não atrasados, então mover $j$ para a posição imediatamente posterior a $i$ gera uma seqüência na qual o atraso ponderado total não aumenta. Aplicações sucessivas destas duas regras geram uma seqüência ótima que satisfaz as condições deste lema.

Teorema 2.6 Suponha que as tarefas estão com os pesos agregados e ordenadas em ordem crescente dos tempos de conclusão, isto é, $d_{1} \leq d_{2} \leq \cdots \leq d_{n}$. Seja $k$ a tarefa com o maior tempo de processamento. Entấo existe algum inteiro $\delta, 0 \leq \delta \leq n-k$, tal que existe uma seqüência ótima $\pi$ na qual $k$ é precedido por todas as tarefas $j$ tais que $j \leq k+\delta$, e seguido por todas as tarefas $j$ tais que $j>k+\delta$.

Prova Seja $C_{k}^{\prime}$ o maior tempo de finalização possível da tarefa $k$ em qualquer seqüência que seja ótima com respeito aos tempos de conclusão $d_{1}, d_{2}, \ldots, d_{n}$. Seja $\pi$ a seqüência ótima com respeito aos tempos de conclusão $d_{1}, d_{2}, \ldots, d_{k-1}, d_{k}^{\prime}=\max \left\{C_{k}^{\prime}, d_{k}\right\}, d_{k+1}, \ldots, d_{n}$ e que satisfaz as condições do Lema 2.2 com respeito a estes tempos de conclusão. Seja $C_{k}$ o tempo de finalização da tarefa $k$ em $\pi$. Pelo Lema 2.1, $\pi$ é ótima com respeito aos tempos de conclusão originais. Desta forma $C_{k} \leq d_{k}^{\prime}$. A tarefa $k$ não pode ser precedida em $\pi$ por nenhuma tarefa $j$ tal que $d_{j}>d_{k}^{\prime}$, senão a tarefa $j$ também não estaria atrasada, violando as condições do Lema 2.2. E a tarefa $k$ deve ser precedida por todas as tarefas $j$ tais que $d_{j} \leq d_{k}^{\prime}$. Escolha $\delta$ como o maior inteiro tal que $d_{k+\delta} \leq d_{k}^{\prime}$ e o teorema está provado.

O algoritmo que apresentaremos calcula, para cada $j \geq k$, um escalonamento ótimo no qual o conjunto de tarefas $I_{1}=\{1, \ldots, j\} \backslash\{k\}$ é escalonado antes de $k$ e o conjunto $I_{2}=\{j+1, \ldots, n\}$ é escalonado depois de $k$. Desta forma, para cada $j$, o problema se divide em dois subproblemas. No primeiro problema, as tarefas em $I_{1}$ devem ser escalonadas otimamente começando no tempo $t_{1}=0$. No segundo problema, as tarefas em $I_{2}$ devem ser escalonadas otimamente começando no tempo $t_{2}=\sum_{i=1}^{j} p_{i}$. Isto sugere o seguinte procedimento recursivo Seq $(t, I)$, que calcula uma seqüência ótima $\sigma^{*}$ para o conjunto de tarefas $I$ começando no tempo $t$. 
Seq $(t, I)$

1. SE $I=\emptyset \operatorname{ENTÃO} \sigma^{*}:=$ seqüência vazia SENÃO

INÍCIO

2. Seja $i_{1}<i_{2}<\cdots<i_{r}$ as tarefas em $I$;

3. Encontre $i_{k} \operatorname{com} p_{i_{k}}:=\max \left\{p_{i} \mid i \in I\right\}$;

4. $f^{*}:=\infty$;

5. PARA $j:=1$ ATÉ $r$ FAÇA INÍCIO

6. $\quad I_{1}:=\left\{i_{\nu} \mid 1 \leq \nu \leq j ; \nu \neq k\right\} ; t_{1}:=t$;

7. $\sigma_{1}:=\operatorname{Seq}\left(t_{1}, I_{1}\right)$;

8. $I_{2}:=\left\{i_{\nu} \mid j<\nu \leq r\right\} ; t_{2}:=t+\sum_{\nu=1}^{j} p_{i_{\nu}}$;

9. $\quad \sigma_{2}:=\operatorname{Seq}\left(t_{2}, I_{2}\right)$

10. $\sigma:=\sigma_{1} \circ i_{k} \circ \sigma_{2}$;

11. Calcule o valor ótimo $f(\sigma, t)$ para $\sigma$;

12. SE $f(\sigma, t)<f^{*}$ ENT $\tilde{A} O$ INÍCIO

13. $\sigma^{*}:=\sigma$;

14. $f^{*}:=f(\sigma, t)$;

FIM

FIM

FIM

15. RETORNE $\left(\sigma^{*}\right)$

Podemos estabelecer um limite para o tempo de execução deste algoritmo. Os conjuntos $I$ que aparecem nos argumentos do procedimento são da forma

$$
I_{i, j, k}:=\left\{\nu \mid i \leq \nu \leq j ; p_{\nu}<p_{k}\right\}
$$

ou seja, eles são completamente caracterizados pela tripla de índices $i, j, k$. Também temos no máximo $p:=\sum_{j=1}^{n} p_{j}$ valores diferentes para $t$. Assim precisamos chamar o procedimento Seq $(t, I)$ no máximo $O\left(n^{3} p\right)$ vezes. Além disso, para um $k$ fixo, todos os valores $\max \left\{p_{\nu} \mid \nu \in I_{i j k}\right\}$ para $i, j=1, \ldots, n$, $i<j$ podem ser calculados em $O\left(n^{2}\right)$. Com isso a complexidade computacional para todos os Passos 3 é $O\left(n^{3}\right)$. Para cada chamada do procedimento recursivo os outros passos podem ser calculados em tempo constante. Desta forma temos um algoritmo com tempo de execução $O\left(n^{3} p\right)$ ou $O\left(n^{4} p_{\max }\right)$, onde $p_{\max }=\max \left\{p_{i} \mid i=1, \ldots, n\right\}$. 


\subsection{Chegadas não simultâneas}

Nos problemas tratados nas seções anteriores mostramos situações em que todas as tarefas estão simultaneamente disponíveis para processamento. Chamamos esta versão do problema de estática. Entretanto, muitos problemas de seqüenciamento requerem que diferentes tempos de chegada sejam considerados.

No caso em que existem diferentes tempos de chegada, o conjunto de tarefas a serem escalonadas muda com o tempo, dando origem a uma versão dinâmica do problema de uma única máquina. Uma conseqüência imediata de permitir diferentes tempos de chegada é a necessidade de reexaminarmos restrições sobre ociosidade da máquina e continuidade na execução de uma tarefa.

\begin{tabular}{cccc} 
Tarefa $j$ & $r_{j}$ & $p_{j}$ & $d_{j}$ \\
\hline 1 & 0 & 5 & 7 \\
2 & 1 & 2 & 2
\end{tabular}

Tabela 2.6: Seqüenciamento de duas tarefas.

Para ilustrarmos a importância desses dois fatores, considere o exemplo da Tabela 2.6 de duas tarefas, no qual o atraso total é o critério de otimização. Existe somente uma seqüência que satisfaz as restrições de ociosidade da máquina e continuidade na execução, ou seja, a seqüência $1-2$ da Figura 2.2-a. Esta seqüência possui um atraso total de 5. Quando permitimos que a máquina fique ociosa durante algum tempo, a seqüência 2 - 1 (Figura 2.2-b) gera um atraso total de 2 . Se permitirmos que uma tarefa possa ser interrompida durante a execução e retomada, após um certo tempo, no ponto em que a interrupção ocorreu, então um atraso total de 1 é gerado, como mostrado na Figura 2.2-c.

O tipo de interrupção ilustrado na Figura 2.2-c é chamado de modo de interrupção-retomado, pois o processamento pode ser retomado do ponto no qual a interrupção ocorreu. Em outras palavras, o tempo total de processamento requerido pela tarefa $j$ é sempre $p_{j}$ e não é afetado pelo número de vezes que a tarefa é interrompida. No caso em que a interrupção-retomado se aplica, a ociosidade da máquina nunca é benéfica.

O extremo oposto é o caso no qual uma tarefa deve ser iniciada novamente a cada vez que é interrompida. Esse tipo de interrupção é chamado de 


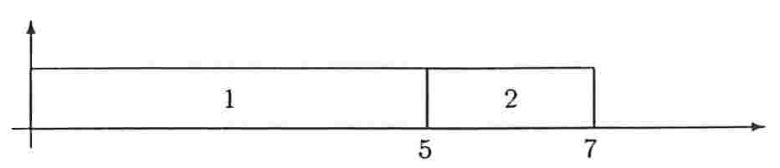

(a)

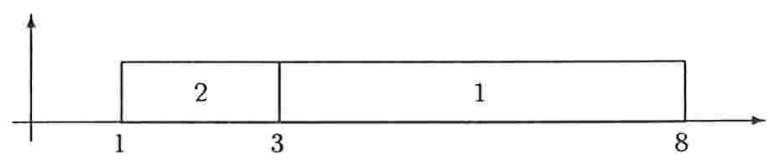

(b)

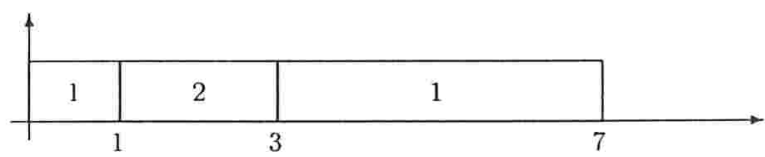

(c)

Figura 2.2: Três diferentes escalonamentos para o Exemplo 2.1.

modo de interrupção-repetição, por razões óbvias. No modo de interrupçãorepetição não há razão para se iniciar o processamento de uma tarefa a menos que esse possa ser completado, exceto se não puder existir máquina ociosa devido a restrições tecnológicas.

Considere o caso de minimizar $T_{\max }$ num problema dinâmico onde a interrupção-repetição se aplica. Nesse caso a regra ótima é: sempre mantenha a máquina escalonada para a tarefa disponivel com o tempo de conclusão mais próximo [Bak74]. A máquina é escalonada nos tempos de chegada e finalização da seguinte forma:

1. Em cada finalização de uma tarefa, examine o conjunto de tarefas disponíveis e escalone a máquina para processar a tarefa com o tempo de conclusão menor;

2. A cada chegada de uma nova tarefa, compare o tempo de conclusão da nova tarefa disponível $j$ com o tempo de conclusão da tarefa que está sendo processada. Se $d_{j}$ for menor, permita que a tarefa $j$ interrompa a tarefa que está sendo processada; caso contrário adicione a nova tarefa à lista de tarefas disponíveis.

Neste caso, a informação vital $d_{j}$, que é a base para a decisão de escalonamento, não muda com o tempo.

Por outro lado, considere o problema de minimizar $\bar{F}$. A regra ótima é: sempre mantenha a máquina escalonada para a tarefa disponível com o 
menor tempo restante de processamento [Bak74]. A informação vital neste caso é o tempo de processamento restante para o término da tarefa, que muda durante o processamento. Dessa forma, uma tarefa que entra no sistema com um grande $p_{j}$ (e relativa baixa prioridade) após alguns processamentos parciais possuirá um tempo de processamento restante menor (e uma prioridade maior). Esta regra de seqüenciamento dinâmico é conhecida como seqüenciamento pelo menor tempo de processamento restante (SRPT).

\subsection{Tarefas dependentes}

Outro tipo de restrição típica em problemas de escalonamento é a restrição tecnológica, representada pela existência de precedência entre tarefas. A presença de tais restrições algumas vezes reflete a imposição de prioridades externas, reduz o conjunto de soluções viáveis e pode tornar o problema ainda mais difícil.

A existência de restrições tecnológicas numa seqüência de tarefas é dada por um ordenamento parcial entre as tarefas baseado numa relação de precedência. A notação $i<j$ denota o fato que a tarefa $i$ precede a tarefa $j$. Em outras palavras, a tarefa $j$ não pode começar até que a tarefa $i$ esteja completa. Quando $i<j$, a tarefa $i$ é predecessora da tarefa $j$, e a tarefa $j$ é sucessora da tarefa $i$. A tarefa $i$ é também chamada de predecessora direta da tarefa $j$ (denotada por $i \ll j$ ) se não existe uma tarefa $k$ tal que $i<k<j$.

\subsubsection{Generalização do seqüenciamento EDD}

Um dos poucos resultados para tarefas independentes, ou seja, sem relação de precedência, que podem ser estendidos para conjuntos de tarefas dependentes sem maiores modificações é a minimização de $L_{\max }$ e $T_{\max }$. Para um conjunto de tarefas independentes, foi mostrado que o seqüenciamento EDD é ótimo. Agora suponha que um conjunto de tarefas dependentes deva ser escalonado. Defina:

$$
d_{j}^{\prime}=\min \left\{d_{j}, \min \left\{d_{i} \mid j<i\right\}\right\}
$$

Ou seja, $d_{j}^{\prime}$ ou é o tempo de conclusão da tarefa $j$ ou o menor tempo de conclusão entre os sucessores de $j$.

Uma seqüência viável que minimize $L_{\max }$ e $T_{\max }$ pode ser construída satisfazendo as restrições de precedencia e escalonando as tarefas em ordem crescente de $d_{j}^{\prime}$. 
Teorema 2.7 No problema de uma única máquina com restrições de precedência arbitrárias, $L_{\max }$ e $T_{\max }$ são minimizadas pela seqüência

$$
d_{[1]}^{\prime} \leq d_{[2]}^{\prime} \leq \cdots \leq d_{[n]}^{\prime} .
$$

Prova Seja $S$ uma seqüência viável que não obedece o ordenamento $d^{\prime}$ especificado. Desta forma deve existir um par de tarefas adjacente $i$ e $j$ na seqüência $S$, com $j$ seguindo $i$, tal que $d_{i}^{\prime}>d_{j}^{\prime}$. Seja $S^{\prime}$ a seqüência obtida pela troca de posições das tarefas $i$ e $j$ na seqüência (esta troca não pode violar as restrições de precedência uma vez que $i<j$ implicaria $\left.d_{i}^{\prime} \leq d_{j}^{\prime}\right)$. Existem dois casos a serem considerados:

1. $d_{i}>d_{j}$

Neste caso o valor de $L_{\max }\left(T_{\max }\right)$ associado ao escalonamento $S^{\prime}$ é no mínimo tão bom quanto o valor associado ao escalonamento $S$, exatamente pela mesma razão que foi utilizada no teorema das tarefas independentes (Teorema 2.5), ou seja, $L_{\max }\left(S^{\prime}\right) \leq L_{\max }(S)$.

2. $d_{i} \leq d_{j}$

Uma vez que $d_{j}^{\prime}<d_{i}^{\prime}$ por hipótese, deve existir uma tarefa $k$ com $j<k$ e $d_{k}<d_{j}$. Também $d_{k}=d_{j}^{\prime}<d_{i}^{\prime} \leq d_{i}$, e assim $d_{k}<d_{i}$. Uma vez que ambos os escalonamentos $S$ e $S^{\prime}$ são viáveis, segue que $C_{k}>C_{j}$ e $C_{k}>C_{i}$ (em ambos os escalonamentos). Portanto

$$
\begin{aligned}
& C_{k}-d_{k}>C_{i}-d_{i}, \\
& C_{k}-d_{k}>C_{j}-d_{j},
\end{aligned}
$$

em ambos os escalonamentos, e $L_{\max }$ não pode ocorrer para a tarefa $i$ ou para a tarefa $j$. Conseqüentemente $L_{\max }\left(S^{\prime}\right)=L_{\max }(S)$.

Combinando esses dois casos, determinamos que $L_{\max }\left(S^{\prime}\right) \leq L_{\max }(S)$, que permite ao argumento da troca de pares adjacentes de tarefas ser invocado para provar a otimalidade.

\subsection{Tempos de ajuste com dependência da se- qüência}

Em muitos problemas reais os tempos de ajuste da máquina dependem do tipo da tarefa que acabou de ser completada, como também da próxima tarefa 
que será executada. Em tais situações não é válido incorporar o tempo de ajuste da tarefa $j$ no tempo de processamento $p_{j}$, e nesses casos algumas modificações devem ser feitas. Podemos expressar o intervalo de tempo no qual a tarefa $j$ ocupa a máquina por $s_{i j}+p_{j}$, sendo $i$ a tarefa que precede $j$ na seqüência, $s_{i j}$ o tempo de ajuste requerido para a tarefa $j$ depois que a tarefa $i$ é completada e $p_{j}$ o tempo de processamento direto requerido para completar a tarefa $j$.

No problema básico com uma única máquina, o tempo para completar todas as tarefas é uma constante ${ }^{6}$. A quantidade de tempo requerida para completar todas as tarefas é chamada de makespan e é denotada por $C_{\max }$. Com tempos de ajuste dependentes da seqüência, entretanto, o makespan depende da seqüência escolhida:

$$
\begin{aligned}
& F_{[1]}=s_{[0],[1]}+p_{[1]} \\
& F_{[2]}=s_{[1],[2]}+p_{[2]}+F_{[1]} \\
& F_{[n]}=s_{[n-1],[n]}+p_{[n]}+F_{[n-1]}
\end{aligned}
$$

onde o estado 0 corresponde ao estado inicial.

Se o estado $n+1$ for tratado como um estado terminal idêntido ao estado 0 , então o makespan escalonado será:

$$
C_{\max }=F_{[n]}+s_{[n],[n+1]}=\sum_{j=1}^{n+1} s_{[j-1],[j]}+\sum_{j=1}^{n} p_{j} .
$$

Como a segunda somatória da Equação 2.5 é uma constante, o problema de minimizar o makespan é equivalente ao de minimizar a primeira somatória. Esta soma representa o tempo total não-produtivo na seqüência total.

Neste caso podemos considerar o problema do caixeiro viajante associado ao problema do escalonamento. O problema do caixeiro viajante é um problema clássico de Otimização Combinatória em que são dadas $n$ cidades e o objetivo é encontrar uma rota que passa pelas cidades e minimiza a distância total percorrida. No problema do seqüenciamento, $s_{i j}$ (o tempo de ajuste para a tarefa $i$ quando ela imediatamente segue a tarefa $j$ ) corresponde à distância entre $i$ e $j$. Neste caso, o problema é assimétrico, já que o tempo de ajuste ao passar de $i$ para $j$ não precisa ser necessariamente o mesmo que o tempo de passar de $j$ para $i$.

\footnotetext{
${ }^{6}$ Estamos considerando todos os tempos de chegada como zero.
} 


\begin{tabular}{|c|c|c|}
\hline Problema & Complexidade & Referência \\
\hline $1 \mid$ prec $; r_{j} \mid C_{\max }$ & $O\left(n^{2}\right)$ & [Law73] \\
\hline $1 \mid$ prec $; r_{j} ; p_{j}=p \mid L_{\max }$ & $O\left(n^{3} \log \log n\right)$ & \\
\hline $1 \mid$ prec $\mid f_{\max }$ & $O\left(n^{2}\right)$ & [Law73] \\
\hline $1 \mid$ prec $; r_{j} ; p_{j}=1 \mid f_{\max }$ & $O\left(n^{2}\right)$ & \\
\hline $1 \mid$ prec $; r_{j} ;$ pmtn $\mid f_{\max }$ & $O\left(n^{2}\right)$ & [BLLK83] \\
\hline $1 \mid r_{j} ;$ pmtn $\mid \sum C_{j}$ & $O(n \log n)$ & [Bak74] \\
\hline $1 \mid$ prec $; r_{j} ; p_{j}=p \mid \sum C_{j}$ & $O\left(n^{2}\right)$ & \\
\hline $\begin{array}{c}1 \| U_{j} \\
1\left|p m t n ; r_{j}\right| \sum U_{j}\end{array}$ & $\begin{array}{l}O(n \log n) \\
O\left(n^{5}\right)\end{array}$ & $\begin{array}{l}{[\text { Moo68] }} \\
\text { [Law90] }\end{array}$ \\
\hline $1\left|r_{j} ; p_{j}=1\right| \sum f_{j}$ & $O\left(n^{3}\right)$ & \\
\hline $1 \| \sum w_{j} U_{j}$ & Pseudo- $\mathcal{P}$ & [LM69] \\
\hline $1 \mid r_{j} ;$ pmtn $\mid \sum w_{j} U_{j}$ & Pseudo- $\mathcal{P}$ & [Law90] \\
\hline $1 \| \sum T_{j}$ & Pseudo- $\mathcal{P}$ & [Law77] \\
\hline $1 \| \sum w_{j} U_{j}$ & $\mathcal{N} \mathcal{P}$-difícil & {$[\operatorname{Kar} 72]$} \\
\hline 1||$\sum T_{j}$ & $\mathcal{N P}$-difícil & [DL90] \\
\hline $1\left|r_{j}\right| L_{\max }$ & ${ }^{*} \mathcal{N} \mathcal{P}$-difícil & [LKB77] \\
\hline $1\left|r_{j}\right| \sum C_{j}$ & ${ }^{*} \mathcal{N} \mathcal{P}$-difícil & [LKB77] \\
\hline $1 \mid$ prec $\mid \sum C_{j}$ & ${ }^{*} \mathcal{N} \mathcal{P}$-difícil & [LK78] \\
\hline $1 \mid$ prec $; p_{j}=1 \mid \sum w_{j} C_{j}$ & ${ }^{*} \mathcal{N} \mathcal{P}$-difícil & [LK78] \\
\hline $1\left|r_{j} ; p m t n\right| \sum w_{j} C_{j}$ & ${ }^{*} \mathcal{N} \mathcal{P}$-difícil & [LLLK84] \\
\hline $1 \| \sum w_{j} T_{j}$ & ${ }^{*} \mathcal{N} \mathcal{P}$-difícil & [LKB77] \\
\hline
\end{tabular}

Figura 2.3: Principais resultados envolvendo problemas de escalonamento com uma única máquina.

\subsection{Principais resultados}

$\mathrm{Na}$ Tabela 2.3 estão contidos os principais resultados para os problemas de escalonamento envolvendo uma única máquina [Bru98]. Nesta tabela os problemas são listados em sua forma mais simples, utilizando as reduções de função objetivo e restrição esquematizadas nas Figuras 1.1 e 1.2, respectivamente. Para os problemas polinomiais informamos a ordem de grandeza de seu tempo de processamento, ou caso contrário informamos se existe algum algoritmo pseudo-polinomial para resolvê-lo ou se o problema é $\mathcal{N} \mathcal{P}$-difícil ou $\mathcal{N} \mathcal{P}$-difícil no sentido forte (denotado por ${ }^{*} \mathcal{N} \mathcal{P}$-difícil na tabela). E ainda, a referencia na qual pode ser encontrado o algoritmo que resulta no tempo de processamento ou a demonstração do resultado citado. 


\section{Capítulo 3}

\section{Seqüenciamento de tarefas em máquinas paralelas}

\subsection{Máquinas paralelas idênticas e tarefas in- dependentes}

O contexto mais simples para a investigação dos efeitos do processamento paralelo é o problema do seqüenciamento com várias máquinas paralelas idênticas. Como no modelo básico, suponha que existam $n$ tarefas que necessitam de uma única operação, simultaneamente disponíveis no tempo zero. Também suponha que existam $m$ máquinas idênticas disponíveis para processamento. Neste caso também é possível utilizarmos as medidas fundamentais de desempenho, sendo que as decisões do escalonamento refletirão o paralelismo dos recursos.

\subsubsection{Minimização do makespan}

No modelo com uma única máquina o makespan é uma constante para qualquer seqüência de $n$ tarefas dadas $^{1}$, ou seja, não há nenhum problema de makespan a ser considerado no caso de uma única máquina. Isto decorre do fato de que não melhoramos o makespan deixando a única máquina ociosa com todas as tarefas a serem escalonadas disponíveis no instante inicial e nem tão pouco deixando a máquina ociosa mais do que o necessário se os tempos

\footnotetext{
${ }^{1}$ Considerando todos os tempos de chegada como zero.
} 
de chegada forem arbitrários. No caso de máquinas múltiplas, entretanto, o problema do makespan não é mais trivial.

Um resultado básico para o problema do makespan foi apresentado por McNaughton [McN59] para o caso em que as tarefas são independentes e interrupção é permitida. Com interrupção permitida, o processamento de uma tarefa pode ser interrompido e o processamento restante pode ser completado posteriormente, talvez em uma máquina diferente. A propriedade central é que o makespan $C_{\max }$ é dado por

$$
C_{\max }=\max \left\{\frac{1}{m} \sum_{j=1}^{n} p_{j}, \max \left\{p_{j} \mid 1 \leq j \leq n\right\}\right\} .
$$

A Equação 3.1 nos diz que as máquinas serão inteiramente utilizadas durante um escalonamento ótimo ou a duração da maior tarefa determinará o makespan. Um método para construir um escalonamento ótimo é descrito no Algoritmo 3.1.

\section{Algoritmo 3.1 - Algoritmo de McNaughton (Para minimizar $C_{\max }$ com $m$ máquinas paralelas idênticas e interrupção de tarefas)}

Passo 1 Selecione uma tarefa qualquer para começar na máquina 1 no tempo zero;

Passo 2 Escolha qualquer tarefa não escalonada e a escalone na mesma máquina. Repita esse passo até que a máquina esteja ocupada além do tempo $C_{\max }$ (ou até que todas as tarefas estejam escalonadas);

Passo 3 Reescalone o tempo de processamento que ultrapassou $C_{\max }$ para a próxima máquina, começando no tempo zero. Retorne ao Passo 2.

É válido notar que esse problema não necessariamente possui uma solução única, e o Algoritmo 3.1 produz somente um dentre os escalonamentos ótimos potenciais. Em particular, o Algoritmo 3.1 não leva em conta a minimização do número de interrupções. Considerando que um pequeno tempo de ajuste está envolvido em cada interrupção, o algoritmo deve ser modificado para produzir escalonamentos ótimos.

Se a interrupção de tarefas não for permitida, o problema de minimizar o makespan se torna mais difícil. Um procedimento heurístico simples mas efetivo para a construção de um escalonamento envolve o uso do escalonamento pelo maior tempo de processamento (LPT) como regra. 


\section{Algoritmo 3.2 - Procedimento heurístico para minimizar $C_{\max }$}

Passo 1 Construa um ordenamento LPT das tarefas;

Passo 2 Escalone as tarefas em ordem, atribuindo cada tarefa à máquina com a menor quantidade de processamento atribuída.

O Algoritmo 3.2 não garante um makespan ótimo. A eficiência desse algoritmo foi investigada como parte de um estudo experimental realizado por Kedia [Ked70].

Podemos construir uma formulação para esse problema utilizando programação inteira. Seja $y$ o makespan e $x_{i j}$ uma variável indicadora definida como segue

$$
x_{i j}= \begin{cases}1 & \text { se a tarefa } i \text { é atribuída à máquina } j ; \\ 0 & \text { caso contrário. }\end{cases}
$$

Dessa forma, uma atribuição viável escalonará a tarefa $i$ a somente uma máquina, ou seja,

$$
\sum_{j=1}^{m} x_{i j}=1, \quad 1 \leq i \leq n
$$

Considerando que o makespan deve ser pelo menos tão grande quanto o tempo de processamento atribuído à máquina, temos

$$
y \geq \sum_{i=1}^{n} p_{i} x_{i j}, \quad 1 \leq j \leq m .
$$

Com isso a formulação completa será:

$$
\begin{array}{lll}
\operatorname{minimize} & y & \\
\text { sujeito a } & y \geq \sum_{i=1}^{n} p_{i} x_{i j}, & 1 \leq j \leq m \\
& \sum_{j=1}^{m} x_{i j}=1, & 1 \leq i \leq n \\
& x_{i j} \geq 0 \quad \text { e inteiro } &
\end{array}
$$

Esta formulação contém $(m+n)$ restrições com $m n+1$ variáveis.

\subsubsection{Minimização do tempo de execução médio e do tempo de execução médio ponderado}

A generalização das propriedades de seqüenciamentos ótimos de modelos com uma única máquina para máquinas paralelas é direta para $\bar{F}$ e mais difícil para $\bar{F}_{w}$. 
Considere primeiramente o problema de minimizar $\bar{F}$ em $m$ máquinas paralelas idênticas e com todas as tarefas disponíveis no instante inicial. Um escalonamento ótimo pode ser construído atribuindo as $m$ tarefas mais longas a $m$ máquinas diferentes, as próximas $m$ tarefas mais longas a $m$ diferentes máquinas, e assim sucessivamente, até que todas as tarefas estejam alocadas [Bak74]. Esta construção pode ser interpretada como um procedimento de atribuição $m$-tarefas-por-vez, mas deve ser observado que existem vários escalonamentos ótimos, uma vez que as atribuições individuais de tarefas a máquinas não são especificadas em nenhum estágio do algoritmo. Também não existe a necessidade de considerar interrupção.

O Algoritmo 3.3 foi elaborado modificando-se o procedimento de atribuição $m$-tarefas-por-vez para uma-tarefa-por-vez.

\section{Algoritmo 3.3 - Minimizando $\bar{F}$ com máquinas paralelas idênticas}

Passo 1 Construa um ordenamento SPT de todas as tarefas;

Passo 2 Atribua a próxima tarefa da lista ordenada de tarefas à máquina com a menor quantidade de processamento alocada (resolva os empates arbitrariamente). Repita até que todas as tarefas estejam alocadas.

Exceto pelos empates, este algoritmo produzirá um escalonamento único e este será um dos escalonamentos que podem ser produzidos pelo procedimento $m$-tarefas-por-vez. Intuitivamente a otimalidade deste algoritmo reside no fato de que cada máquina conterá, no conjunto, a menor seqüência SPT possível. De acordo com o Teorema 2.1, cada máquina produzirá uma seqüência individual ótima. Desta forma o algoritmo garante o seqüenciamento ótimo das $m$ máquinas.

Por outro lado, quando $\bar{F}_{w}$ é a regra considerada, algumas formulações através de programação dinâmica são utilizadas. Neste caso, duas propriedades teóricas se aplicam a esse problema. Primeira, qualquer solução ótima deve produzir o ordenamento WSPT das tarefas em cada máquina ${ }^{2}$. Segunda, um limite inferior do valor ótimo de $\bar{F}_{w}$ pode ser computado, como

\footnotetext{
${ }^{2}$ Se isso não for verdade, uma simples troca de pares de tarefas na máquina pode melhorar o escalonamento.
} 
descrito por Eastman, Even e Isaacs [EEI64]. Vamos denotar por:

$B(1)=$ o valor mínimo de $\bar{F}_{w}$ para o dado conjunto de tarefas se existir somente uma máquina (obtido via WSPT);

$B(m)=$ o valor mínimo de $\bar{F}_{w}$ para o dado conjunto de tarefas se existirem $m$ máquinas (obtido através da atribuição de cada tarefa a uma máquina diferente).

Dessa forma o limite inferior para $m$ máquinas $(1 \leq m \leq n)$ é:

$$
B(m)=\frac{1}{2 m}[(m-1) B(1)+2 B(n)] .
$$

Vale notar que $B=\max \{B(1), B(m)\}$ é também um limite inferior válido.

Um estudo experimental que compara várias regras heurísticas é descrito em [BM73]. O procedimento $m$-tarefas-por-vez é incorporado dentro de um procedimento heurístico denotado por $H_{m}$ (Algoritmo 3.4).

Algoritmo 3.4 - Algoritmo $H_{m}$

Passo 1 Construa uma lista com prioridade com todas as tarefas não escalonadas, utilizando alguma regra $\mathcal{R}$;

Passo 2 Atribua as primeiras $m$ tarefas da lista a diferentes máquinas. Repita o Passo 2 até que todas as tarefas estejam escalonadas e então vá para o Passo 3;

Passo 3 Aplique o seqüenciamento WSPT a cada máquina.

$\mathrm{O}$ procedimento heurístico complementar, chamado $H_{1}$, atribui uma tarefa por vez (Algoritmo 3.5).

Algoritmo 3.5 - Algoritmo $H_{1}$

Passo 1 Construa uma lista com prioridade com todas as tarefas não escalonadas, utilizando alguma regra $\mathcal{R}$;

Passo 2 Atribua a primeira tarefa da lista à máquina com a menor quantidade de processamento alocada. Repita até que todas as tarefas tenham sido escalonadas. Então vá para o Passo 3;

Passo 3 Aplique o seqüenciamento WSPT a cada máquina. 
O estudo comparativo realizado em [BM73] examinou algumas variações desses procedimentos heurísticos e concluiu que seus comportamentos relativos são difíceis de caracterizar. O estudo concluiu que:

1. $H_{1}$ e $H_{m}$, em geral, produzem escalonamentos diferentes, e cada método produzirá um escalonamento diferente quando o ordenamento inicial $\mathcal{R}$ for variado;

2. Nenhum dos dois métodos pode garantir otimalidade;

3. Não parece ser possível identificar uma regra ótima $\mathcal{R}$ para $H_{1}$ ou para $H_{m}$.

Entretanto, a variação mais efetiva dos procedimentos considerados no estudo foi $H_{1}$ utilizado com $\mathcal{R}=$ WSPT. Esta combinação não somente produziu o melhor escalonamento na maioria dos problemas, mas também possui as características do Algoritmo 3.3.

\subsection{Máquinas paralelas idênticas e tarefas de- pendentes}

Quando o conjunto de tarefas é dependente, o problema de minimizar o makespan se torna mais difícil. Os resultados fundamentais para este caso são baseados no trabalho de $\mathrm{Hu}$ [Hu61], que apresentou um mecanismo de rotulação com um algoritmo de escalonamento associado para o problema do makespan.

No caso mais simples, suponha que $p_{j}=1$ para todas as tarefas e que as tarefas formam uma árvore montagem (nenhuma tarefa tem mais do que um sucessor direto). A tarefa sem sucessor é chamada de tarefa terminal em tal árvore. O Algoritmo 3.6 contém uma fase de rotulação seguida por uma fase de escalonamento.

\section{Algoritmo 3.6 - Algoritmo de $\mathrm{Hu}$ (Para minimizar o makespan pa- ra tarefas dependentes com os mesmos $p_{j}$ )}

Fase de rotulação ${ }^{3}$

\footnotetext{
${ }^{3}$ Podemos considerar esta fase de rotulação como um caso específico de uma Ordenação Topológica.
} 
Passo 1 Atribua o rótulo 0 a cada tarefa terminal;

Passo 2 Para cada tarefa $j$, identifique o único $k$ para o qual $j \ll k$, $e$ atribua à tarefa $j$ o rótulo $\alpha_{j}=\alpha_{k}+1$;

Fase de escalonamento

Passo 3a Se o número de tarefas sem predecessor é menor ou igual a $m$, escalone essas tarefas seguidamente, deixando as máquinas em excesso ociosas. Vá para o Passo 4 .

Passo 3b Se o número de tarefas sem predecessor ultrapassar $m$, escalone as $m$ tarefas com os maiores rótulos (resolvendo os empates arbitrariamente). Vá para o Passo 4 .

Passo 4 Remova as tarefas escalonadas do problema e retorne ao Passo 3 até que todas as tarefas estejam escalonadas.

O esquema de rotulação de Hu parece ser efetivo em outras situações mais gerais. Por exemplo, se os tempos de processamento não forem iguais mas as tarefas puderem ser interrompidas, o algoritmo ainda pode ser utilizado para encontrar o makespan mínimo sob certas condições. Se as tarefas não podem ser interrompidas, o algoritmo não garante uma solução ótima, mas usualmente produzirá boas soluções.

Para lidar com tempos de processamento diferentes e com estruturas de precedência mais gerais do que uma árvore, o esquema de rotulação tem de ser generalizado como segue:

Fase de rotulação

Passo 1 Atribua a cada tarefa terminal um rótulo igual a seu tempo de processamento;

Passo 2 Atribua à tarefa $j$ o rótulo $\alpha_{j}=p_{j}+\max \left\{\alpha_{i} \mid j \ll i\right\}$.

Neste caso, da mesma forma, o algoritmo não pode garantir escalonamentos ótimos mas gera escalonamentos satisfatórios. 


\subsection{Principais Resultados}

$\mathrm{Na}$ Tabela 3.1 podemos observar os principais resultados que envolvem o seqüenciamento de tarefas em máquinas paralelas. Todos esses problemas também foram listados em sua forma mais simples, analogamente aos resultados para uma única máquina mostrados na Tabela 2.3. 


\begin{tabular}{|c|c|c|}
\hline Problema & Complexidade & Referência \\
\hline$P \mid$ pmtn $\mid C_{\max }$ & $O(n)$ & [McN59] \\
\hline$P\left|p_{i}=p ; r_{i} ; d_{i}\right| C_{\max }$ & $O\left(n^{3} \log \log n\right)$ & [Sim83] \\
\hline$Q\left|p m t n ; r_{i}\right| C_{\max }$ & $O(n \log n+m n)$ & [LLLK84] \\
\hline$Q\left|p_{i}=1 ; r_{i}\right| C_{\max }$ & $O(n \log n)$ & [DLLdV90] \\
\hline$Q|p m t n| L_{\max }$ & $O(n \log n+m n)$ & [LLLK84] \\
\hline$Q\left|p m t n ; r_{i} ; d_{i}\right|-$ & $O\left(m n^{3}\right)$ & [FG86] \\
\hline$R\left|p m t n ; r_{i}\right| L_{\max }$ & prog. linear & [LL78] \\
\hline$Q\left|p_{i}=1\right| f_{\max }$ & $O\left(n^{2}\right)$ & [GLLK79] \\
\hline$P 2\left|p_{i}=p ; p m t n ; r_{i}\right| \sum C_{i}$ & $O(n \log n)$ & [HL90] \\
\hline$P\left|p_{i}=p ; r_{i} ; d_{i}\right| \sum C_{i}$ & $O\left(n^{3} \log \log n\right)$ & [Sim83] \\
\hline$Q|p m t n| \sum C_{i}$ & $O(n \log n+m n)$ & [LLLK84] \\
\hline$R \| \sum C_{i}$ & $O\left(m n^{3}\right)$ & {$[\mathrm{BCS} 74]^{\circ}$} \\
\hline$P\left|p_{i}=1\right| \sum w_{i} C_{i}$ & $O(n \log n)$ & [McN59] \\
\hline$P\left|p_{i}=1 ; p m t n\right| \sum w_{i} C_{i}$ & $O(n \log n)$ & [McN59] \\
\hline$Q m \mid$ pmtn $\mid \sum U_{i}$ & $O\left(n^{3(m-1)}\right)$ & [Law79] \\
\hline$P\left|p_{i}=1 ; r_{i}\right| \sum f_{i}$ & $O\left(m n^{3}\right)$ & \\
\hline$Q\left|p_{i}=1\right| \sum f_{i}$ & $O\left(n^{3}\right)$ & [GLLK79] \\
\hline$P 2 \mid$ prec $; p_{i}=p \mid C_{\max }$ & $O\left(n^{\log 7}\right)$ & [CG72] \\
\hline$P 2 \mid$ prec $; p_{i}=1 ; r_{i} \mid L_{\max }$ & $O\left(n^{3} \log n\right)$ & [GJ77] \\
\hline$P 2 \mid$ prec $; p_{i}=1 \mid L_{\max }$ & $O\left(n^{\log 7}\right)$ & [GJ76] \\
\hline$Q 2 \mid$ prec; pmtn $\mid L_{\max }$ & $O\left(n^{2}\right)$ & [Law82] \\
\hline$Q 2 \mid$ prec $;$ pmtn $; r_{i} \mid L_{\max }$ & $O\left(n^{6}\right)$ & [Law82] \\
\hline$P 2 \mid$ prec $; p_{i}=p \mid \sum C_{i}$ & $O\left(n^{\log 7}\right)$ & [CG72] \\
\hline$P 2 \| C_{\max }$ & $\mathcal{N} \mathcal{P}$-difícil & \\
\hline$P 2 \| \sum w_{i} C_{i}$ & $\mathcal{N} \mathcal{P}-\mathrm{d}$ & [BCS74] \\
\hline$P 2 \mid$ pmtn $\mid \sum w_{i} C_{i}$ & $\mathcal{N} \mathcal{P}$-difícil & [BCS74] \\
\hline$P 2\left|p m t n ; r_{i}\right| \sum U_{i}$ & $\mathcal{N} \mathcal{P}$-difícil & [DLW92] \\
\hline$P|p m t n| \sum U_{i}$ & $\mathcal{N P}$-difícil & [Law83] \\
\hline$P 2 \mid$ prec $; p_{i}=1 \mid \sum w_{i} C_{i}$ & 1 Máquina & \\
\hline$P \| C_{\max }$ & ${ }^{*} \mathcal{N} \mathcal{P}$-difícil & [GJ78] \\
\hline$P 2\left|r_{i}\right| \sum C_{i}$ & ${ }^{*} \mathcal{N} \mathcal{P}$-difícil & \\
\hline$P 2\left|p m t n ; r_{i}\right| \sum C_{i}$ & ${ }^{*} \mathcal{N} \mathcal{P}$-difícil & [DLY90] \\
\hline$P|| \sum w_{i} C_{i}$ & ${ }^{*} \mathcal{N} \mathcal{P}$-difícil & \\
\hline$P 2\left|p m t n ; r_{i}\right| \sum w_{i} C_{i}$ & 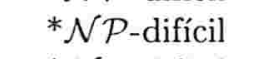 & [LLLK84] \\
\hline$P|p m t n| \sum w_{i} C_{i}$ & ${ }^{*} \mathcal{N} \mathcal{P}$-difícil & \\
\hline$P\left|p m t n ; p_{i}=p ; r_{i}\right| \sum w_{i} C_{i}$ & ${ }^{*} \mathcal{N} \mathcal{P}$-difícil & [LY90] \\
\hline$R\left|p m t n ; r_{i}\right| \sum U_{i}$ & ${ }^{*} \mathcal{N} \mathcal{P}$-difícil & [DL91] \\
\hline$P \mid$ prec $; p_{\imath}=1 \mid C_{\max }$ & ${ }^{*} \mathcal{N} \mathcal{P}$-difícil & [Ull75] \\
\hline$P \mid$ prec $;$ pmtn $; p_{i}=1 \mid C_{\max }$ & ${ }^{*} \mathcal{N} \mathcal{P}$-difícil & [Ull76] \\
\hline$P \mid$ prec $; p_{i}=1 \mid \sum C_{i}$ & ${ }^{*} \mathcal{N} \mathcal{P}$-difícil & [LK78] \\
\hline
\end{tabular}

Figura 3.1: Principais resultados envolvendo problemas de escalonamento com máquinas paralelas. 


\section{Parte II}

\section{Estudo de Caso}




\section{Capítulo 4}

\section{Apresentação do problema}

Neste capítulo descreveremos o problema proposto. Esse problema foi encontrado em uma empresa que produz revestimentos cerâmicos e consiste do desenvolvimento de um método de escalonamento automatizado da produção.

Este estudo consistirá dos seguintes passos:

1. Identificação das características físicas de todo o processo, como por exemplo, a disposição e o fluxo da linha de produção.

2. Observação das restrições que são aplicadas à produção. Neste item devemos considerar dois tipos de restrições: aquelas impostas pela linha de produção e também as impostas por regras implícitas.

3. Formulação de modelos relaxados e posteriores refinamentos até conseguirmos chegar o mais próximo possível do problema real.

4. Comparação dos resultados obtidos pelos modelos com os dados coletados na empresa.

\subsection{Disposição da linha de produção}

Nesta seção descreveremos a estrutura da linha de produção da empresa. Toda produção é realizada em duas unidades de produção fisicamente separadas, representadas respectivamente nas Figuras 4.1 e 4.2. 


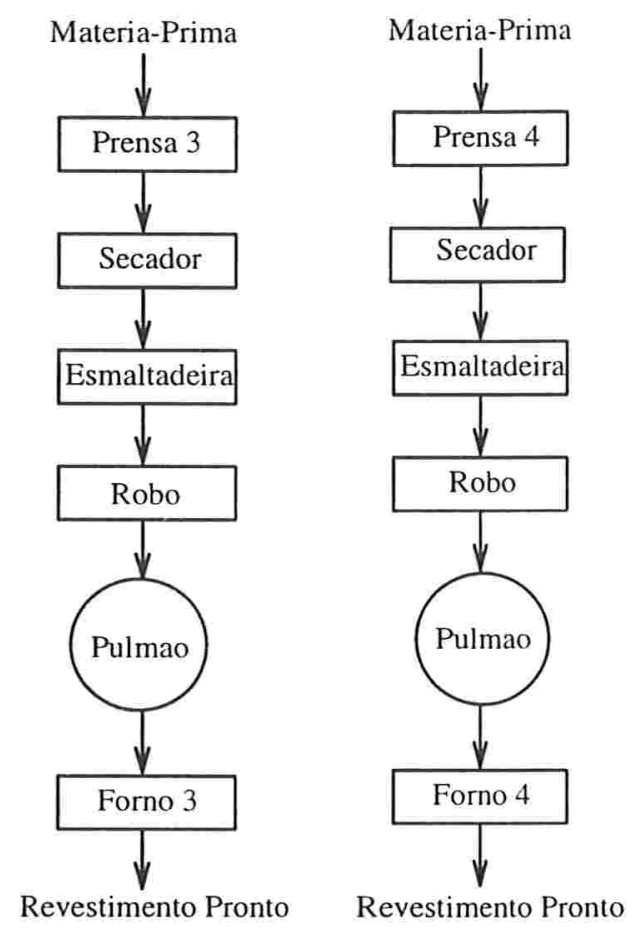

Figura 4.1: Representação esquemática da Unidade I de produção.

Em linhas gerais, o processo de produção dos revestimentos consiste da seguinte seqüência:

Matéria-prima $\rightarrow$ Prensa $\rightarrow$ Forno $\rightarrow$ Revestimento Pronto

O ciclo de operação se inicia com a prensagem da matéria-prima, que no caso é argila em pó. Após a prensagem, através de uma esteira rolante, o revestimento passa por um secador que reduz sua umidade. Em seguida, o revestimento seco é esmaltado ao passar pela esmaltadeira. É durante esta parte do processo que se formará o padrão do revestimento. Estando esmaltado, o revestimento é armazenado em carrinhos automaticamente por um robô, sendo que esses carrinhos ficam aguardando em um espaço reservado, denominado pulmão, até entrarem no forno para serem queimados. Após a queima, o processo de produção é encerrado efetuando-se, na saída do forno, a embalagem do produto em caixas.

A seguir, descreveremos em detalhe cada parte que compõe a linha de produção, e mencionaremos também as restrições tecnológicas associadas. 

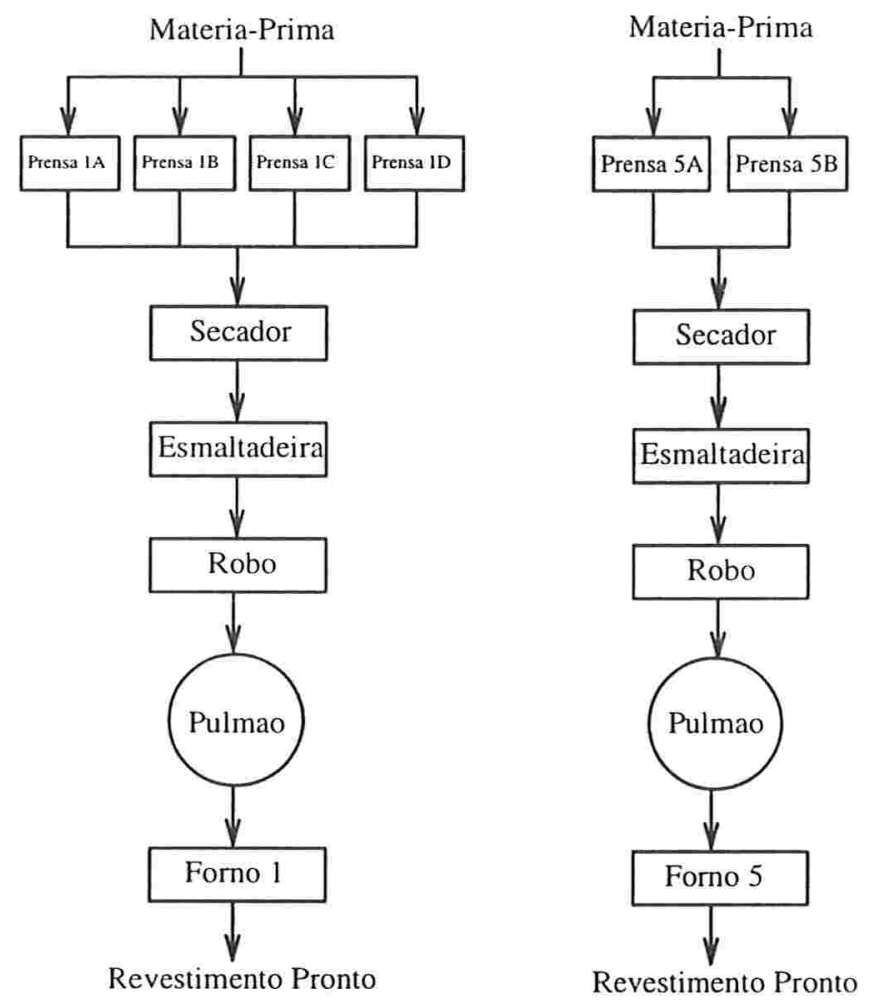

Figura 4.2: Representação esquemática da Unidade II de produção.

\subsubsection{As prensas}

A linha de produção possui um total de oito prensas hidráulicas automáticas, de características diferentes. Essas prensas são continuamente alimentadas de matéria-prima através de esteiras rolantes, sendo observadas por apenas um operador cuja função é detectar eventuais problemas.

A Unidade I possui duas prensas (Prensas 3 e 4) e a Unidade II possui seis prensas, sendo quatro para a linha 1 (Prensas 1A, 1B, 1C e 1D) e duas para a linha 5 (Prensas 5A e 5B $)^{1}$. Devido à disposição dos equipamentos, tanto na linha 1 como na linha 5 somente uma prensa é utilizada por vez. Todas as prensas trabalham a uma taxa média de 11 batidas/minuto.

A empresa produz revestimentos dos seguintes tamanhos: $7 \frac{1}{2} \times 7 \frac{1}{2}, 10 \times$ $10,10 \times 20$ e $20 \times 20 \mathrm{~cm}$. Para cada tamanho temos um molde utilizado pelas prensas, sendo esses moldes denominados estampos. Na Tabela 4.1

\footnotetext{
${ }^{1}$ Procuramos descrever o processo de produção através da utilização dos mesmos nomes dos equipamentos adotados pela empresa.
} 


\begin{tabular}{c|cccccccc} 
Tipo \Prensa & $1 \mathrm{~A}$ & $1 \mathrm{~B}$ & $1 \mathrm{C}$ & $1 \mathrm{D}$ & 3 & 4 & $5 \mathrm{~A}$ & $5 \mathrm{~B}$ \\
\hline $7 \frac{1}{2} \times 7 \frac{1}{2}$ & - & - & - & - & 16 & 16 & - & - \\
$10 \times 10$ & - & - & - & - & 12 & 12 & 12 & 12 \\
$10 \times 20$ & 8 & 8 & 8 & 8 & - & - & 8 & 8 \\
$20 \times 20$ & 3 & 3 & 3 & 3 & - & - & - & -
\end{tabular}

Tabela 4.1: Número de revestimentos produzidos pelas prensas por batida.

podemos observar quais os possíveis tipos de revestimentos produzidos por cada uma das prensas e a respectiva quantidade de peças produzidas em cada batida da prensa para cada tipo, ou seja, a quantidade de peças que cada estampo produz.

Como a linha de produção é contínua, a manutenção das prensas e dos estampos tem de ser realizada durante a produção. Aproximadamente a cada 30 dias os tuchos dos estampos devem ser trocados, paralisando a prensa por 0,5 horas. A cada 60 dias os quadros dos estampos são virados, uma operação que dura em média 2 horas. Por fim, a cada 4 meses o estampo deve ser substituído para uma reforma geral. Como nessa linha de produção quatro tipos de revestimentos são produzidos, a troca de estampos leva um tempo maior se o tipo for mudado. Isto se deve a um ajuste das prensas. Quando não há troca do tipo, a troca de estampo leva 4 horas. No outro caso, 4 horas extras são necessárias.

Todos esses dados são relevantes para a formulação do processo. Por exemplo, com relação à troca de estampos, para as linhas 3 e 4 esses tempos devem ser considerados pelo modelo, enquanto que para as linhas 1 e 5 esses tempos deixam de existir devido a existência de mais de uma prensa disponível. Ou seja, como existem mais prensas, pode-se deixar cada uma com um tipo de estampo diferente.

\subsubsection{Os secadores}

Nessa linha de produção os secadores são peças que não influenciam o ritmo da produção. Esses secadores são regulados de acordo com a freqüência de batidas das prensas e da umidade da matéria-prima que entra no sistema. Esse processo de regulagem dos secadores não influencia o ritmo de produção uma vez que é realizado instantaneamente por um operador. 


\subsubsection{As esmaltadeiras}

As esmaltadeiras, ao contrário dos secadores, possuem um papel mais ativo na dinâmica da linha de produção. Como são máquinas que trabalham com esmaltes líquidos, os bicos injetores desses esmaltes necessitam ser limpos periodicamente. Essa limpeza dura em média 0,5 horas e é realizada aproximadamente a cada 6 horas, de preferência durante a troca de turno dos funcionários.

Por outro lado, como é o esmalte que dá a característica da padronagem de cada revestimento, ao passar da produção de um pedido de um determinado padrão para outro de padrão diferente é necessário realizar a troca de esmaltes. Esse processo envolve a lavagem da esmaltadeira e dura em média 1,5 hora. Esse também é outro fator a ser considerado no estudo do problema.

\subsubsection{Os robôs}

Os robôs, como o próprio nome já diz, são máquinas automáticas que nada mais fazem do que retirar os revestimentos já prensados, secos e esmaltados da esteira e colocá-los em carrinhos para aguardarem a queima. Esses robôs também não influenciam o processo de produção uma vez que podem ser regulados para acompanhar o ritmo da produção e trabalham independentes do tipo do revestimento que está sendo produzido.

\subsubsection{Os pulmões}

O pulmão é o nome dado a uma determinada área onde os carrinhos contendo os revestimentos já esmaltados ficam aguardando. Sua existência se deve a uma restrição dos fornos (cujo funcionamento será detalhado na próxima seção) que têm de operar continuamente e não podem ser desligados ou ficarem ociosos. Assim, deve existir uma área onde peças a serem queimadas ficam estocadas. A capacidade do pulmão é limitada, podendo garantir o funcionamento do forno por aproximadamente 8 horas. Dessa forma, o gerente de produção administra esse espaço através do controle da velocidade das prensas, podendo eventualmente parar o processo de prensagem quando da ocorrência de problemas com os fornos e conseqüente utilização máxima desse espaço.

Caso uma prensa ou outra máquina da linha quebre, o estoque do pulmão 


\begin{tabular}{c|cccc} 
Tipo \Forno & 1 & 3 & 4 & 5 \\
\hline $7 \frac{1}{2} \times 7 \frac{1}{2}$ & - & 1050 & 1000 & - \\
$10 \times 10$ & - & 900 & 800 & 1900 \\
$10 \times 20$ & 1300 & - & - & 1900 \\
$20 \times 20$ & 1150 & - & - & -
\end{tabular}

Tabela 4.2: Velocidade de queima dos fornos em $\mathrm{m}^{2} /$ dia.

garante o funcionamento dos fornos. Se isso não for feito, revestimentos já queimados, ou seja, prontos, terão de ser passados novamente pelo forno, evitando que este fique ocioso. Naturalmente esse fato é indesejável pois um revestimento queimado por duas vezes não pode ser aproveitado na venda.

\subsubsection{Os fornos}

Os fornos consistem da parte final da linha de produção. Os revestimentos depois de queimados passam por um controle de qualidade e são embalados na saída do forno, estando portanto prontos para serem entregues aos respectivos clientes. Na Tabela 4.2 podemos observar as respectivas velocidades de queima de cada forno para cada tipo de revestimento.

Esses fornos trabalham continuamente, mas a cada 45 dias são desligados para a limpeza dos rolos que conduzem os revestimentos. Esse processo dura em média de 3 a 4 dias, sendo que nesse tempo estão incluídas 24 horas para o desligamento e conseqüente resfriamento do forno, e mais 24 horas para a retomada da temperatura normal de queima. Durante a manutenção dos fornos é também realizada a manutenção preventiva de toda a linha de produção.

Devemos salientar que a restrição mais importante com relação aos fornos é que esses devem ser utilizados continuamente, caso contrário, acabam quebrando devido a limitações técnicas.

\subsection{Considerações sobre o sistema de produ- ção}

Nesta seção descreveremos como o programador decide em que ordem os pedidos devem ser atendidos. Nessa empresa o programador da produção, a 
cada semana, recebe a ordem de produção de todos os pedidos confirmados. Nesta ordem de produção estão incluídas a quantidade, o padrão e a data de entrega dos pedidos. De posse da ordem de produção de um pedido ele verifica se é necessária a compra de matéria-prima para produzi-lo. Caso essa matéria-prima não esteja disponível em estoque, o processo de cotação, compra e entrega desse material pelo fornecedor dura em média de 7 a 10 dias. A empresa que visitamos, em geral, trabalha com estoques muito baixos de matéria-prima, exceto a argila, que é estocada em grandes quantidades. Dessa forma é quase impossível iniciar imediatamente o processamento de um novo pedido pela linha de produção devido à falta de matéria-prima.

De posse de todas essas informações o programador realiza o escalonamento da produção utilizando um critério próprio (aplicado inconscientemente) desenvolvido através de anos de experiência nesta atividade de programação da produção.

Uma outra característica do sistema é que uma vez iniciada a produção de um determinado pedido, este é processado até o seu término, ou seja, não é possível interromper a produção de um pedido para o início da produção de outro. Essa restrição existe devido à dificuldade de se obter o mesmo tom dos esmaltes e também pelas perdas associadas ao ajuste do forno quando se muda o padrão ou o tamanho do revestimento a ser queimado.

\subsection{Simplificação do problema}

Com vistas a apresentar uma modelagem matemática para o problema vamos considerar quais simplificações podem ser feitas sem prejuízo à modelagem. Assim podemos evitar o excesso de informações na formulação, somente considerando as grandezas que realmente possuem um papel ativo.

Para o caso do problema em questão um item que claramente não necessita ser considerado na formulação é o secador. Como já foi explicado anteriormente, os secadores são adaptados à dinâmica da linha de produção sem nenhum custo, ou seja, o ajuste dos secadores não afeta o ritmo da produção. O mesmo vale para os robôs, que não precisam ser considerados pois são peças sem nenhuma influência direta no processo.

Obviamente quando consideramos que os secadores e os robôs são peças da linha de produção que não influenciam a dinâmica do processo estamos considerando seus estados normais de operação. Pois sendo máquinas, sempre estão sujeitos a defeitos e conseqüente paralisações, como outra máquina 


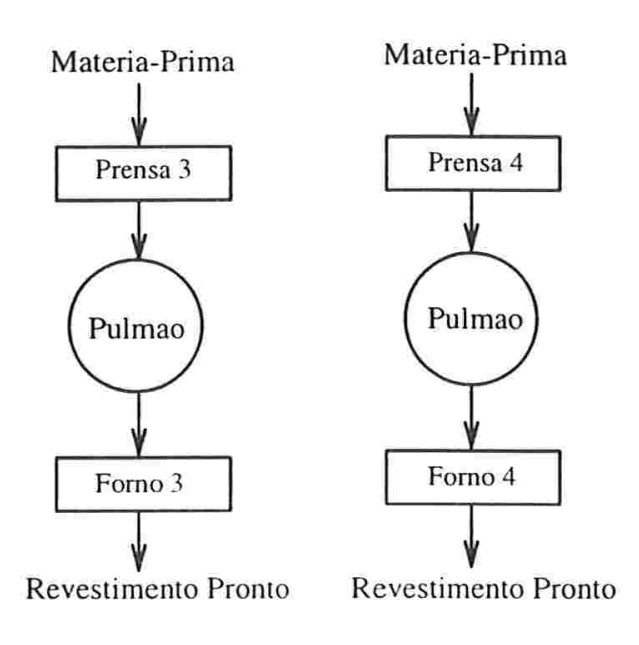

Unidade I

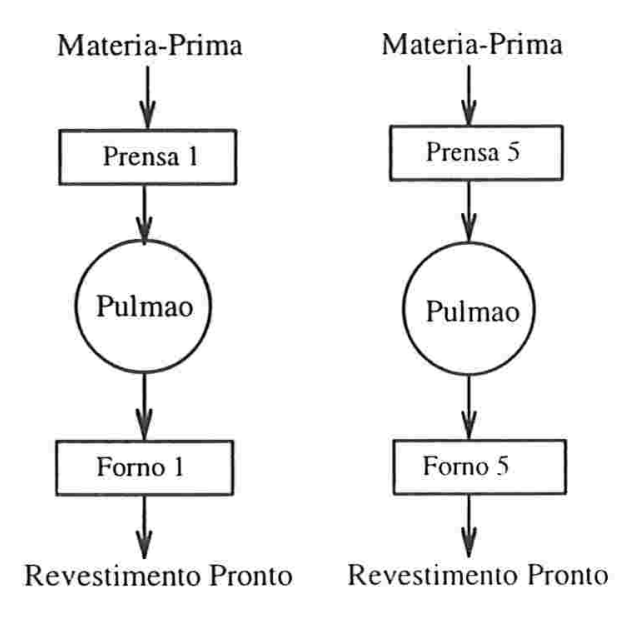

Unidade II

Figura 4.3: Representação simplificada da linha de produção.

qualquer. Naturalmente, se qualquer uma dessas partes quebrar, a linha de produção como um todo (exceto os fornos) tem de ser paralisada.

Como já foi descrito previamente, as esmaltadeiras possuem um papel mais ativo sobre a linha de produção pois necessitam de uma limpeza periódica, paralisando a linha de produção por 0,5 hora a cada 6 horas. Como essa limpeza deve ser efetuada sempre, independente do tipo do revestimento que está sendo produzido, este também é um fator que pode ser omitido diretamente da formulação. Ou seja, essa informação pode ser incluída nos tempos de ajuste de cada pedido, pois de acordo com o tamanho do pedido e a prensa que ele utilizará, saberemos o número de paralisações que serão realizadas durante a produção desse pedido para a limpeza das esmaltadeiras. Essa informação tem de ser considerada na formulação pois afeta o tempo de finalização dos pedidos.

O pulmão, consistindo apenas de um espaço físico para a estocagem dos revestimentos aguardando a queima, também pode ser omitido da formulação. Embora, como já foi descrito anteriormente, seja o pulmão uma área limitada, em condições normais de operação da linha de produção sua capacidade nunca será esgotada pois a velocidade das prensas é regulada compativelmente com a capacidade de queima dos respectivos fornos, evitando dessa forma sua superlotação.

Outra simplificação que adotamos consiste em considerar todas as 4 pren- 
sas da linha 1 como sendo uma única prensa, e o mesmo para as duas prensas da linha 5. Essa simplificação é viável já que nunca se utiliza duas prensas de uma linha ao mesmo tempo. O único fator que diferencia uma linha que contém uma única prensa de outra que contém várias prensas é o tempo de ajuste, já que todas as prensas das linhas 1 e 5 podem produzir os mesmos tipos de revestimentos (Tabela 4.1). E essa diferença entre tempos de ajuste para cada linha pode ser considerada na formulação.

Dessa forma, considerando todas as simplificações descritas acima, podemos representar as Unidades I e II de produção (Figuras 4.1 e 4.2) de uma forma simplificada, como representado na Figura 4.3. Podemos notar que a linha de produção simplificada consiste somente de 4 prensas e 4 fornos (dois pares para cada unidade de produção), estando cada prensa interligada com um único forno. Como esse novo esquema de produção possui todas as características fundamentais do processo real, é sobre ele que faremos a formulação do problema. 


\section{Capítulo 5}

\section{Modelagem}

Neste capítulo procuraremos desenvolver um modelo matemático para o processo de produção descrito no capítulo anterior. Consideraremos somente o problema simplificado com apenas uma máquina, representando uma linha de produção individualmente.

\subsection{Uma única máquina}

Nesta seção estudaremos o problema utilizando uma simplificação da estrutura contida na Figura 4.3. Como o item da linha de produção que mais influencia a dinâmica do sistema como um todo é a prensa, consideraremos um problema simplificado que consiste apenas de uma única máquina. Essa máquina tem como entrada a matéria-prima e após a prensagem e queima, que são efetuadas por essa única máquina, o revestimento já sai pronto. $\mathrm{Na}$ Figura 5.1 podemos ver um esquema desta estrutura.

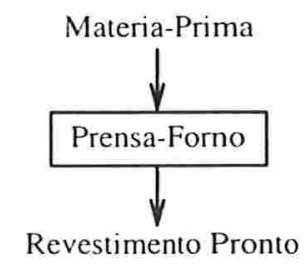

Figura 5.1: Esquema de produção com uma única máquina.

Basicamente o problema que trataremos consiste do escalonamento de alguns pedidos que necessitam serem prensados e depois queimados. Os revestimentos que compõem os pedidos podem ser dos seguintes tipos: $7 \frac{1}{2}$ 
$\times 7 \frac{1}{2}, 10 \times 10,10 \times 20$ e $20 \times 20 \mathrm{~cm}$. Neste caso consideraremos que a única máquina disponível prensa e queima todos os tipos de revestimentos. Como revestimentos de tipos diferentes podem ser produzidos, a máquina necessita de um tempo de ajuste para a troca dos estampos, caso haja a mudança do tipo do revestimento que estava sendo produzido, e também para a limpeza da parte da máquina que os esmalta ${ }^{1}$. Além do tipo de revestimento, cada pedido possui também uma demanda que representa a quantidade de revestimento requerida pelo pedido e uma data de entrega (tempo de conclusão) para o cliente.

\subsection{Formalização}

Em escalonamento chama-se cada pedido de tarefa ${ }^{2}$. Note que as tarefas são independentes, e ainda, podem ser processadas apenas na máquina disponível na fábrica. Portanto, o problema que estudamos consiste em obter o melhor escalonamento possível, de acordo com a função objetivo escolhida, de tarefas independentes em uma única máquina.

Esse problema possui ainda tempos de ajuste dependentes da seqüência, ou seja, tempos de ajuste que dependem tanto do tipo do pedido que acabou de ser completado, como também do próximo pedido que será executado.

De acordo com a classificação acima e o objetivo do problema real que o modelo deve representar, podemos utilizar como critério de otimização a minimização do:

a) tempo de execução total;

b) número de tarefas atrasadas; ou

c) atraso total.

Uma vez classificado o problema, devemos verificar qual abordagem se adequa melhor ao tratamento matemático do mesmo.

\footnotetext{
${ }^{1} \mathrm{Da}$ forma como foi definido o tempo de ajuste, ele claramente não pode ser simplesmente adicionado ao tempo de processamento de cada tarefa, uma vez que depende do tipo da tarefa que foi produzido anteriormente.

${ }^{2}$ Desse ponto em diante passaremos a adotar os termos tarefa e pedido para a mesma coisa indistintamente, dependendo da situação.
} 


\subsection{Modelagem}

A modelagem desse problema será realizada utilizando-se a abordagem por programação linear inteira. Iniciaremos a descrição considerando uma simplificação do problema: não consideraremos tempos de conclusão e tempos de ajuste. Ou seja, o problema consistirá apenas do escalonamento de $n$ pedidos independentes, todos disponíveis para escalonamento no instante inicial, sendo que a única grandeza associada a cada pedido $j$ é seu tempo de processamento $p_{j}$. Posteriormente incluiremos na formulação os tempos de ajuste, de conclusão dos pedidos e também as restrições sobre matéria-prima.

Vamos denotar por $t_{j}$ o instante de tempo no qual o processamento da tarefa $j$ inicia, com $t_{j}=0,1, \ldots, T$. Para essa definição supomos que é conhecido o instante $T$, que constituirá um limite superior para as variáveis $t_{j}$.

\section{Restrições de não interferência}

Suponha que as tarefas $j$ e $k$ possuam os tempos de processamento $p_{j}$ e $p_{k}$, respectivamente. Dessa forma temos de prever no modelo que duas tarefas não ocupem a máquina ao mesmo tempo. Para isso temos de alocar a uma tarefa tempo suficiente para que a outra não possa iniciar seu processamento antes que a primeira esteja completa, ou seja,

$$
t_{j}-t_{k} \geq p_{k} \quad \text { ou } \quad t_{k}-t_{j} \geq p_{j} .
$$

Para expressarmos a Condição 5.1 acima na forma de uma ou mais desigualdades lineares envolvendo variáveis inteiras, definimos uma variável inteira $y_{j k}$ e consideramos as seguintes restrições:

$$
\begin{gathered}
\left(T+p_{k}\right) y_{j k}+\left(t_{j}-t_{k}\right) \geq p_{k} \\
\left(T+p_{j}\right)\left(1-y_{j k}\right)+\left(t_{k}-t_{j}\right) \geq p_{j} \\
y_{j k} \in\{0,1\} .
\end{gathered}
$$

A variável $y_{j k}$ pode assumir apenas os valores 0 ou 1. Pela Condição 5.2, caso $t_{j}$ seja menor que $t_{k}$ (ou seja, a tarefa $j$ inicia sua execução antes da tarefa $k$ ), então $y_{j k}$ deve ser necessariamente 1 . No outro caso $\left(t_{k}<t_{j}\right)$, a Condição 5.3 garante que a variável $y_{j k}=0$. Com isso, $y_{j k}$ é 1 se e somente se a tarefa $j$ inicia antes da tarefa $k$. Ou seja, as restriçōes garantem que não haverá sobreposição de tarefas. Considere o caso em que $y_{j k}=1$. Neste 
caso a Condição 5.2 está satisfeita. A Restrição 5.3 garante que a tarefa $k$ só iniciará depois que a tarefa $j$ for concluída.

$\mathrm{Na}$ formalização final do problema devemos incluir as Restrições $5.2 \mathrm{e}$ 5.3 acima para todo par de tarefas $j k$. Com as restrições acima já modelamos o problema de escalonamento de $n$ tarefas independentes em uma única máquina. Nosso próximo passo é considerar os tempos de ajuste na formulação.

\section{Tempos de ajuste}

Lembramos que há quatro tipos de tarefas, e o tempo de ajuste da máquina é maior se a tarefa a ser executada for de um tipo diferente do tipo da tarefa que acabou de ser concluída. Seja $S$ o tempo de ajuste quando houver troca de tipos e $s$ quando os tipos forem iguais. No tempo de ajuste $S$ consideraremos o tempo necessário para a troca de estampos da prensa mais o tempo necessário para a lavagem da esmaltadeira. Analogamente, em $s$ somente consideramos o tempo de lavagem da esmaltadeira ${ }^{3}$.

Considere uma tarefa $j$ do tipo $X$ e duas tarefas $i$ e $k$ do tipo $Y(X \neq Y)$. Dessa forma, a Restrição 5.1 tem de ser substituída por:

$$
\begin{aligned}
& t_{j}-t_{k} \geq p_{k}+S \quad \text { ou } \quad t_{k}-t_{j} \geq p_{j}+S \\
& t_{i}-t_{k} \geq p_{k}+s \quad \text { ou } \quad t_{k}-t_{i} \geq p_{i}+s .
\end{aligned}
$$

De forma análoga ao realizado para a Restrição 5.1, a conversão das Restrições 5.4 e 5.5 em desigualdades lineares é dada por:

$j$ e $k$ de tipos distintos

$$
\begin{gathered}
\left(T+p_{k}+S\right) y_{j k}+\left(t_{j}-t_{k}\right) \geq p_{k}+S \\
\left(T+p_{j}+S\right)\left(1-y_{j k}\right)+\left(t_{k}-t_{j}\right) \geq p_{j}+S \\
y_{j k} \in\{0,1\}
\end{gathered}
$$

$i$ e $k$ do mesmo tipo

$$
\begin{gathered}
\left(T+p_{k}+s\right) y_{i k}+\left(t_{i}-t_{k}\right) \geq p_{k}+s \\
\left(T+p_{i}+s\right)\left(1-y_{i k}\right)+\left(t_{k}-t_{i}\right) \geq p_{i}+s \\
y_{i k} \in\{0,1\} .
\end{gathered}
$$

\footnotetext{
${ }^{3} \mathrm{O}$ tempo de ajuste $s$ poderia ser incorporado diretamente ao tempo de processamento $p_{j}$ de cada tarefa $j$.
} 


\section{Tempos de conclusão}

Outra restrição que devemos considerar em nossa modelagem diz respeito aos tempos de conclusão (datas de entrega) dos pedidos. Nessa formalização consideraremos que para todo pedido $j$ seu tempo de conclusão $d_{j}$ tem de ser respeitado, ou seja, o processamento de todo pedido tem de ser concluído até o tempo de conclusão do mesmo. Essa restrição pode ser expressa pela inequação:

$$
t_{j}+p_{j} \leq d_{j}
$$

\section{Limitação de Recursos}

Como já foi descrito anteriormente, a empresa em questão tem como estratégia manter mínimos os estoques de esmaltes. E ainda, uma vez feito o pedido, o material leva de 7 a 10 dias para estar disponível na linha de produção. Dessa forma temos de incluir em nossa modelagem uma restrição que traduza o nível de estoque de matéria-prima. Isso pode ser realizado através da inclusão dos tempos de chegada $r_{j}$ para cada tarefa. Assim, dada uma tarefa $j$, podemos expressar essa restrição da seguinte forma:

$$
r_{j} \geq \beta_{j}
$$

Ou seja, na grandeza $\beta_{j}$ incluímos a informação de quando a matéria-prima para a produção da tarefa $j$ estará disponível. Por exemplo, caso para uma determinada tarefa $j$ exista em estoque a matéria-prima necessária para sua produção (tanto com relação ao tipo como a quantidade necessária), $\beta_{j}=0$. Caso contrário, se tiver de ser realizado o pedido dessa matéria-prima, $7 \leq$ $\beta_{j} \leq 10$.

Um fato a ser notado é que quando incluímos as restrições de tempos de conclusão e chegada em um mesmo modelo, dependendo da carteira de pedidos considerada podemos obter um problema inviável. Como um exemplo trivial desta situação considere uma carteira com três pedidos com as seguintes características:

\begin{tabular}{c|c|c|c} 
Pedido & Conclusão $(d)$ & Recursos $(\beta)$ & Processamento $(p)$ \\
\hline 1 & 20 & 5 & 10 \\
2 & 20 & 0 & 15 \\
3 & 35 & 10 & 10
\end{tabular}


O escalonamento desta carteira claramente é inviável, uma vez que não conseguimos produzir os pedidos a tempo, dados esses tempos de conclusão.

\section{Estado Inicial}

Outro fato a ser considerado na modelagem do problema é o estado inicial da linha de produção. Ou seja, ao realizarmos o escalonamento de uma carteira de pedidos temos de levar em conta o tipo de revestimento que está sendo produzido no sistema e o tempo que resta até seu término. Esse fato pode ser incluído na modelagem através da criação de uma tarefa fictícia (tarefa 0 ) cujas características correspondem ao estado inicial do sistema. Para forçarmos o modelo a reconhecer essa tarefa 0 como sendo o estado inicial do sistema, incluiremos a seguinte restrição no modelo:

$$
t_{0}=0 \text {. }
$$

\subsection{Minimização do tempo de execução total}

Dado o problema de escalonar um conjunto de $n$ tarefas independentes, podemos utilizar como critério de otimização desse escalonamento a minimização do tempo de execução total. Consideraremos nesse modelo que os tempos de conclusão devem ser obedecidos, pois caso relaxemos essa restrição o escalonamento que minimiza o tempo de execução total é imediato, dado pelo escalonamento inicial de todas as tarefas cujo tipo é o mesmo daquele do estado inicial do sistema ${ }^{4}$ (em qualquer ordem), seguido pelo escalonamento das tarefas dos outros tipos restantes, também em qualquer ordem. Também consideraremos as restrições de não interferência entre tarefas e de tempos de ajuste, além da restrição sobre a limitação de recursos (matéria-prima).

Denotando o tempo de execução total por $t$, o problema então consiste da minimização de $t$ com relação aos inteiros $t_{j}$ e $y_{j k}$, sujeitos às Restrições $5.6-5.12$, e ainda sujeito a:

$$
t_{j}+p_{j} \leq t
$$

Dessa forma, a modelagem final do problema de minimizar o tempo de execução total é dada por:

Minimize $t$

\footnotetext{
${ }^{4} \mathrm{O}$ estoque é praticamente inexistente.
} 
Sujeito a:

$$
\begin{aligned}
& t_{0}=0 \\
& t_{j} \geq \beta_{j}, \quad \forall j \in \mathcal{J} \\
& t_{j}+p_{j} \leq d_{j}, \quad \forall j \in \mathcal{J} \\
& t_{j}+p_{j} \leq t, \quad \forall j \in \mathcal{J} \\
& \left(T+p_{k}+S\right) y_{j k}+\left(t_{j}-t_{k}\right) \geq p_{k}+S \text {. } \\
& \forall j, k \in \mathcal{J} \text { com Tipo }[j] \neq \operatorname{Tipo}[k] \\
& \left(T+p_{j}+S\right)\left(1-y_{j k}\right)+\left(t_{k}-t_{j}\right) \geq p_{j}+S, \\
& \forall j, k \in \mathcal{J} \text { com Tipo }[j] \neq \text { Tipo }[k] \\
& \left(T+p_{k}+s\right) y_{j k}+\left(t_{j}-t_{k}\right) \geq p_{k}+s \text {. } \\
& \forall j, k \in \mathcal{J}(j \neq k) \text { com Tipo }[j]=\text { Tipo }[k] \\
& \left(T+p_{j}+s\right)\left(1-y_{j k}\right)+\left(t_{k}-t_{j}\right) \geq p_{j}+s \text {, } \\
& \forall j, k \in \mathcal{J}(j \neq k) \text { com Tipo }[j]=\text { Tipo }[k] \\
& y_{j k} \in\{0,1\}, \quad \forall j, k \in \mathcal{J}(j \neq k) \\
& t, t_{j} \in Z_{0}^{+}, \quad \forall j \in \mathcal{J}
\end{aligned}
$$

onde consideramos $\mathcal{J}=\{0,1,2, \ldots, n\}$ e $\operatorname{Tipo}[j]$ como sendo o tipo do revestimento correspondente à tarefa $j$. Lembramos que a constante $T$ deve ser escolhida de tal forma que $t_{j} \ll T, \forall j \in \mathcal{J}$.

\subsection{Minimização do número de tarefas atra- sadas}

Em vez de forçarmos nosso modelo a obedecer todos os tempos de conclusão, podemos modificá-lo para que minimize o número de tarefas atrasadas. Ou seja, agora permitiremos que as tarefas possam ser terminadas depois do tempo de conclusão. Essa alteração é interessante pois dessa forma a empresa pode negociar os prazos de entrega dos pedidos que compõem a carteira com seus clientes, visando a melhora da eficiência de sua linha de produção.

Para incluirmos essa modificação em nosso modelo, substituiremos a Restrição 5.10 por:

$$
\begin{gathered}
t_{j}+p_{j}-T z_{j} \leq d_{j} \\
z_{j} \in\{0,1\} .
\end{gathered}
$$


Pela relação acima, se $\left(t_{j}+p_{j}\right) \leq d_{j}$, ou seja, se a tarefa $j$ não está atrasada, então $z_{j}$ pode assumir os valores 0 ou 1 . Por outro lado, se a tarefa $j$ estiver atrasada, $\left(t_{j}+p_{j}\right)>d_{j}$, então necessariamente $z_{j}=1$. Como queremos minimizar o número de tarefas atrasadas, a nova função objetivo será:

$$
\text { Minimize } \sum_{j=0}^{n} z_{j}
$$

Ou seja, o valor ótimo encontrado para a função objetivo nos dará o menor número de tarefas atrasadas.

Com isso o modelo completo que minimiza o número de tarefas atrasadas será dado por:

$$
\begin{aligned}
& \text { Minimize } \sum_{j=0}^{n} z_{j} \\
& \text { Sujeito a: } \\
& t_{0}=0 \\
& t_{j} \geq \beta_{j}, \quad \forall j \in \mathcal{J} \\
& t_{j}+p_{j}-T z_{j} \leq d_{j}, \quad \forall j \in \mathcal{J} \\
& \left(T+p_{k}+S\right) y_{j k}+\left(t_{j}-t_{k}\right) \geq p_{k}+S, \\
& \forall j, k \in \mathcal{J} \text { com Tipo }[j] \neq \text { Tipo }[k] \\
& \left(T+p_{j}+S\right)\left(1-y_{j k}\right)+\left(t_{k}-t_{j}\right) \geq p_{j}+S, \\
& \forall j, k \in \mathcal{J} \text { com Tipo }[j] \neq \text { Tipo }[k] \\
& \left(T+p_{k}+s\right) y_{j k}+\left(t_{j}-t_{k}\right) \geq p_{k}+s, \\
& \forall j, k \in \mathcal{J}(j \neq k) \text { com Tipo }[j]=\operatorname{Tipo}[k] \\
& \left(T+p_{j}+s\right)\left(1-y_{j k}\right)+\left(t_{k}-t_{j}\right) \geq p_{j}+s, \\
& \forall j, k \in \mathcal{J}(j \neq k) \text { com Tipo }[j]=\operatorname{Tipo}[k] \\
& y_{j k} \in\{0,1\}, \quad \forall j, k \in \mathcal{J}(j \neq k) \\
& z_{j} \in\{0,1\}, \quad \forall j \in \mathcal{J} \\
& t_{j} \in Z_{0}^{+}, \quad \forall j \in \mathcal{J}
\end{aligned}
$$

onde consideramos $\mathcal{J}=\{0,1,2, \ldots, n\}$ e Tipo $[j]$ como sendo o tipo do revestimento correspondente à tarefa $j$. Lembramos também que a constante $T$ deve ser escolhida de tal forma que $t_{j} \ll T, \forall j \in \mathcal{J}$.

Diferentemente do caso onde minimizamos o tempo de execução total, nesse modelo a inclusão da restrição de limitação de recursos nunca gerará 
um problema inviável computacionalmente. Entretanto, pode gerar alguns escalonamentos com ociosidade na máquina, o que não é aceitável em situações reais devido às restrições tecnológicas da linha de produção.

Uma outra consideração que devemos fazer é que esse modelo também permite especificarmos quais tarefas podem ser atrasadas e aquelas cujos tempos de conclusão devem ser obedecidos. Por exemplo, se uma dada tarefa $j$ não puder sofrer atraso, basta incluirmos na formulação $z_{j}=0$, ou seja, fixamos o valor da variável $z_{j}$. Neste caso pode ser que o problema se torne inviável.

\subsection{Minimização do atraso total}

Um fato indesejável que pode ocorrer quando minimizamos o número de tarefas atrasadas é um atraso muito grande de determinada tarefa. Para evitarmos esse fato podemos incluir em nosso modelo uma penalidade que seja proporcional ao atraso de cada tarefa.

Para resolvermos esse problema devemos substituir a Restrição 5.15 por:

$$
\begin{gathered}
t_{j}+p_{j}-w_{j} \leq d_{j} \\
w_{j} \in Z_{0}^{+} .
\end{gathered}
$$

Analogamente ao modelo anterior, se a tarefa $j$ não estiver atrasada, $\left(t_{j}+\right.$ $\left.p_{j}\right) \leq d_{j}$, então $w_{j} \geq 0$. No caso em que a tarefa $j$ estiver atrasada, $\left(t_{j}+p_{j}\right)>$ $d_{j}$, então $w_{j}>0$. Para minimizarmos o atraso total, devemos considerar a seguinte função objetivo:

$$
\text { Minimize } \sum_{j=0}^{n} w_{j}
$$

Com isso, o menor atraso total da carteira passa a ser dado pelo valor ótimo da função objetivo.

E assim o modelo final que minimiza o atraso total é:

Minimize $\sum_{j=0}^{n} w_{j}$

Sujeito a:

$$
t_{0}=0
$$




$$
\begin{gathered}
t_{j} \geq \beta_{j}, \quad \forall j \in \mathcal{J} \quad \\
t_{j}+p_{j}-w_{j} \leq d_{j}, \quad \forall j \in \mathcal{J} \\
\left(T+p_{k}+S\right) y_{j k}+\left(t_{j}-t_{k}\right) \geq p_{k}+S, \\
\forall j, k \in \mathcal{J} \operatorname{com} \operatorname{Tipo}[j] \neq \operatorname{Tipo}[k] \\
\left(T+p_{j}+S\right)\left(1-y_{j k}\right)+\left(t_{k}-t_{j}\right) \geq p_{j}+S, \\
\forall j, k \in \mathcal{J} \operatorname{com} \operatorname{Tipo}[j] \neq \operatorname{Tipo}[k] \\
\left(T+p_{k}+s\right) y_{j k}+\left(t_{j}-t_{k}\right) \geq p_{k}+s, \\
\forall j, k \in \mathcal{J}(j \neq k) \operatorname{com} \operatorname{Tipo}[j]=\operatorname{Tipo}[k] \\
\left(T+p_{j}+s\right)\left(1-y_{j k}\right)+\left(t_{k}-t_{j}\right) \geq p_{j}+s, \\
\forall j, k \in \mathcal{J}(j \neq k) \operatorname{com} \operatorname{Tipo}[j]=\operatorname{Tipo}[k] \\
y_{j k} \in\{0,1\}, \quad \forall j, k \in \mathcal{J}(j \neq k) \\
t_{j}, w_{j} \in Z_{0}^{+}, \quad \forall j \in \mathcal{J}
\end{gathered}
$$

onde consideramos $\mathcal{J}=\{0,1,2, \ldots, n\}$ e $\operatorname{Tipo}[j]$ como sendo o tipo do revestimento correspondente à tarefa $j$. Lembramos ainda que a constante $T$ deve ser escolhida de tal forma que $t_{j} \ll T, \forall j \in \mathcal{J}$.

Também podemos refinar esse modelo através da inclusão de um limite máximo de atraso para uma determinada tarefa. Por exemplo, se uma dada tarefa $j$ não puder atrasar mais do que $\gamma_{j}$, adicionamos a seguinte restrição ao modelo:

$$
0 \leq w_{j} \leq \gamma_{j}
$$

Já se a mesma tarefa $j$ tiver de obedecer o seu tempo de conclusão fazemos $w_{j}=0$ no modelo. As mesmas considerações sobre a viabilidade do modelo discutidas na seção anterior também se aplicam neste caso. 


\section{Capítulo 6}

\section{Experimentos computacionais}

Neste capítulo descrevemos os experimentos computacionais do trabalho. Primeiramente descrevemos o processo de organização dos dados coletados na empresa. A seguir fazemos uma análise dessas amostras obtidas e a descrição de todo o tratamento realizado nos dados. Finalmente concluímos com a análise dos resultados.

Outro objetivo deste capítulo é procurar dar uma idéia de como funciona na prática o desenvolvimento da solução de um problema real, desde as visitas à empresa para a formulação do problema e a busca dos dados experimentais até a proposição da solução. Ou seja, deixar descrito como pode se dar a ligação entre a parte acadêmica e o processo de pesquisa de campo. Esperamos deixar claro com essa descrição que esses dois "mundos", acadêmico e prático, embora muito distintos entre si, somente tendem a ganhar quando trabalham em conjunto.

\subsection{Coleta dos dados}

Durante o processo de visitas à empresa foi realizada a coleta dos dados experimentais referentes ao processo de produção como um todo. Na maioria das vezes esses dados foram obtidos de maneira indireta através de conversas com o pessoal de várias áreas da empresa. Grande parte desta informação coletada estava em estado bruto e necessitava de um processo de filtragem para a separação dos dados que seriam efetivamente importantes para a análise do problema. Esse processo naturalmente foi sendo depurado ao longo de toda a pesquisa de campo e posteriormente durante o processo de estudo dos 
dados propriamente ditos.

Durante a pesquisa de campo um problema real com que nos deparamos é que a empresa em questão não mantém nenhuma informação histórica organizada com relação aos escalonamentos realizados. Com isto não há informação sobre a ordem em que os pedidos foram processados, os tempos de conclusão de cada pedido ou até mesmo a carteira de pedidos ao longo do tempo. Naturalmente poderíamos conseguir algumas dessas informações através do exame das notas de faturamento e das listagens de pedidos da empresa. Mas isto seria inviável e a empresa não estava disposta a disponibilizar seus livros de registro para isto.

Esse problema da coleta dos dados foi solucionado através de anotações que o programador da produção mantinha sobre os pedidos processados e a respectiva carteira de pedidos. Entretanto essas anotações eram relativamente recentes. Nestas anotações, além de outras informações fora do propósito deste trabalho, conseguimos o tamanho e o tempo de conclusão de todos os pedidos de aproximadamente três meses e meio consecutivos, para cada um dos quatro tipos de revestimento produzidos pela empresa. Devido à questão do sigilo dos dados, denominamos cada um desses meses respectivamente como Amostra 1,., 4. A Amostra 1 contém os pedidos cujo tempo de conclusão é no primeiro mês, a Amostra 2 os pedidos com tempo de conclusão no mês seguinte e assim sucessivamente. A Amostra 4 corresponde aos pedidos do mês mais recente e estava incompleta.

Após um exame das amostras podemos notar que na grande maioria esses tempos de conclusão estão distribuídos no início, meio e final de cada mês. Esse fato decorre da maneira como esses tempos de conclusão são combinados com os clientes. Desta forma é mais fácil para o programador gerenciar a produção do que com tempos de conclusão distribuídos proporcionalmente ao longo do mês.

Vale ressaltar que nas anotações obtidas constava apenas o tamanho dos pedidos (em $\mathrm{m}^{2}$ ) e o tempo de conclusão real como uma data. Ou seja, esses dados estavam em unidades diferentes. Para colocarmos todos os dados na mesma base, consideramos a velocidade de processamento de cada forno, que como já foi explicado anteriormente é o gargalo do sistema, e assim conseguimos colocar todos os dados na mesma unidade. Isto é, transformamos o tempo de conclusão de data para $m^{2}$. Esta transformação naturalmente depende da velocidade de queima do forno em que o pedido será processado. Por exemplo, se considerarmos um pedido de $500 \mathrm{~m}^{2}$ do tipo $7,5 \times 7,5$ que pode ser produzido nas máquinas das linhas 3 (1050 $\mathrm{m}^{2} /$ dia $)$ e $4\left(1000 \mathrm{~m}^{2} /\right.$ dia $)$, 
com tempo de conclusão para o dia 15 do mês e considerando o dia primeiro do mês como a base inicial, temos os tempos de conclusão 15750 e 15000, respectivamente para as linhas 3 e 4 . Devido a essa conversão de unidades, esse mesmo pedido fica com tempos de conclusão diferentes, dependendo da máquina em que for processado, como vimos no exemplo acima.

\begin{tabular}{|l|c|c|c|c|c|}
\hline & $7,5 \times 7,5$ & $10 \times 10$ & $10 \times 20$ & $20 \times 20$ & Total \\
\hline Amostra 1 & 37 & 84 & 34 & 11 & 166 \\
Amostra 2 & 43 & 58 & 29 & 15 & 145 \\
Amostra 3 & 46 & 66 & 26 & 14 & 152 \\
Amostra 4 & 10 & 72 & 22 & 14 & 118 \\
\hline Total & 136 & 280 & 111 & 54 & 581 \\
\hline
\end{tabular}

Figura 6.1: Número de pedidos (tarefas) para cada amostra.

$\mathrm{Na}$ tabela da Figura 6.1 estão contidos o número de pedidos de cada amostra para cada tipo de revestimento, bem como os totais por tipo, amostra e o total geral de pedidos das amostras conseguidas. Observando esses dados podemos notar que o número de pedidos para as três primeiras amostras (correspondentes aos meses completos) são aproximadamente da mesma ordem. Com relação ao número de pedidos por tipo, a quantidade de pedidos do tipo $10 \times 10$ é relativamente maior do que os outros, seguido pelo tipo $7,5 \times 7,5$ e $10 \times 20$. Finalmente notamos o número reduzido de pedidos do tipo $20 \times 20$, que é menor de todos.

Com os dados da tabela da Figura 6.1 somente conseguimos ter uma idéia da distribuição do número de pedidos da empresa ao longo do tempo. Essa informação é importante pois qualquer solução que adotarmos para o problema esbarra no número de tarefas, que na prática é um limitante importante do tempo de processamento dos algoritmos ou heurísticas para a solução de problemas de escalonamento e seqüenciamento.

O tamanho total em $m^{2}$ das amostras pode ser visto na tabela da Figura 6.2. Esta tabela possui a mesma estrutura da tabela da Figura 6.1, mostrando a soma dos pedidos para cada amostra separado por tipo e os respectivos totais. Com relação aos totais por amostra, podemos notar que para os três primeiros meses completos essa quantidade também é da mesma ordem. Isto acontece pois essa informação reflete a capacidade de produção mensal da empresa. Outro fato é que o tamanho dos pedidos por tipo também segue o mesmo padrão da distribuição do número de pedidos, já descrito anteriormente. 


\begin{tabular}{|l|c|c|c|c|c|}
\hline & $7,5 \times 7,5$ & $10 \times 10$ & $10 \times 20$ & $20 \times 20$ & Total \\
\hline Amostra 1 & 24.197 & 54.754 & 22.250 & 5.290 & 106.491 \\
Amostra 2 & 41.578 & 27.178 & 24.936 & 8.259 & 101.951 \\
Amostra 3 & 21.972 & 39.795 & 23.924 & 16.387 & 102.078 \\
Amostra 4 & 22.225 & 27.890 & 13.011 & 8.476 & 71.602 \\
\hline Total & 109.972 & 149.617 & 84.121 & 38.412 & 382.122 \\
\hline
\end{tabular}

Figura 6.2: Tamanho total dos pedidos para cada amostra.

\begin{tabular}{|l|c|c|c|c|}
\hline & Forno 1 & Forno 3 & Forno 4 & Forno 5 \\
\hline $7,5 \times 7,5$ & - & 31.500 & 30.000 & - \\
$10 \times 10$ & - & 27.000 & 24.000 & 57.000 \\
$10 \times 20$ & 39.000 & - & - & 57.000 \\
$20 \times 20$ & 34.500 & - & - & - \\
\hline
\end{tabular}

Figura 6.3: Capacidade mensal máxima de produção da empresa.

A capacidade mensal máxima de produção de cada linha da empresa, separada por tipo, pode ser vista na tabela da Figura 6.3. Esses dados correspondem ao produto da velocidade de cada forno, em $\mathrm{m}^{2} / \mathrm{dia}$, por um mês de trinta dias. Como já foi descrito anteriormente, esses dados refletem a capacidade máxima (um limite superior teórico) de produção da empresa uma vez que os fornos são o gargalo do sistema.

Outro fato que merece ser mencionado é sobre como esses tempos de conclusão são gerados pela empresa. Como já foi descrito no Capítulo 1, esses tempos de conclusão são previamente combinados com o cliente de acordo com o comprometimento, no momento em que o pedido é efetuado, da capacidade da linha de produção. Assim, ao estipular um tempo de conclusão, o programador da produção, que é o responsável pela especificação dos tempos de conclusão, de certa forma já está realizando o escalonamento. Foi essa informação que conseguimos nas anotações do programador. $\mathrm{Na}$ prática esses dados são de certa forma "viciados", mas por outro lado são dados reais, e os únicos disponíveis.

Como pôde ser observado, até o momento não mencionamos nada sobre os tempos de chegada dos pedidos. Isso ocorreu pois essa informação não existia nas anotações do programador. De certa forma essa informação não é necessária para a solução "prática" do problema pois geralmente a empresa possui uma carteira de pedidos de aproximadamente três meses. Como a 
requisição do material para a produção de um pedido demora aproximadamente de 7 a 10 dias sempre haverá pedidos a serem produzidos. Devido a esse prazo necessário para o pedido da matéria-prima, a empresa, na prática, não combina nenhuma data de entrega menor do que esse período com o cliente. Com isso os tempos de chegada dos pedidos podem ser considerados todos iguais a zero, ou ainda, desconsiderados na formulação. Pudemos chegar a essa conclusão após algum tempo, depois de intercalar várias conversas com o programador da produção e estudo do problema, conseguindo chegar assim a um modelo o mais próximo possível do que ocorre na empresa.

\subsection{Simulações envolvendo PLI}

Nesta seção discutiremos os experimentos computacionais utilizando as modelagens por PLI descritas no capítulo anterior.

Após alguns testes desses modelos com pequenas amostras, pudemos constatar que o tempo de execução necessário para a solução ótima desses problemas na prática era inviável. Por exemplo, para amostras de aproximadamente 15 tarefas a solução ótima era conseguida após algumas horas de processamento em uma estação de trabalho, usando o CPlex para resolver o problema ${ }^{1}$.

Visando contornar esse problema do tempo de execução poderíamos ter relaxado algumas restrições de nosso modelo a fim de obtermos respostas em tempos menores. Entretanto, decidimos investir no desenvolvimento de algoritmos e heurísticas de escalonamento para a solução do problema.

Um fato que pesou para essa decisão é que devido ao caráter aplicado do trabalho, gostaríamos de propor alguma solução que pudesse ser implementada pela empresa sem grandes custos. Se apresentássemos uma solução envolvendo PLI, a empresa, para eventualmente utilizá-la, deveria comprar um pacote (solver) para resolver esse tipo de problema. Por outro lado, um algoritmo implementado, por exemplo, em linguagem $C$, não teria custo real algum.

$\mathrm{Na}$ próxima seção descrevemos o algoritmo que foi implementado.

\footnotetext{
${ }^{1}$ Ocupando $100 \%$ de um processador de uma estação de trabalho Sun 1000 com 4 processadores e 760 Mbytes de memória.
} 


\subsection{Resolvendo o problema 1||$\Sigma T_{j}$}

Analisando o processo produtivo da empresa, a primeira solução que surge para o problema é desenvolver um algoritmo que resolva cada um dos tipos individualmente. Ou seja, um algoritmo que escalone cada um dos tipos de revestimento em máquinas diferentes. Como são quatro tipos e quatro máquinas distintas, a princípio não se tem nenhum problema.

O próximo passo é decidir quais as restrições sobre o problema que temos de resolver. De acordo com a descrição do problema as variáveis que devem ser levadas em conta na formulação é somente o tempo de processamento e o tempo de conclusão. Pela característica particular do problema não precisamos considerar os tempos de chegada. Como resolveremos para uma máquina por vez produzindo um único tipo, também nào necessitamos considerar os tempos de ajuste. Dessa forma somente nos resta decidir qual a função objetivo do problema.

Durante as conversas com o programador da produção não conseguimos determinar um objetivo específico de seus escalonamentos. Entretanto, um fato que ficou claro é que a empresa procura evitar atrasos na entrega de seus pedidos, tentando na medida do possível sempre cumprir aquilo que foi acordado com os clientes. Desta forma uma função objetivo razoável para o problema seria a minimização da soma dos atrasos de todos os pedidos envolvidos no escalonamento. Essa função se justifica pois não seria uma boa política somente minimizar o número de tarefas atrasadas (pense no exemplo de um escalonamento que produzisse uma única tarefa atrasada mas com um atraso gigantesco. Como ficaria esse cliente ?). Utilizando a notação já descrita para problemas de escalonamento, o problema que resolveremos será: 1||$\sum T_{j}$.

\begin{tabular}{|l|c|c|c|c|c|c|c|c|}
\hline Tipo & \multicolumn{2}{|c|}{$7,5 \times 7,5$} & \multicolumn{3}{|c|}{$10 \times 10$} & \multicolumn{2}{c|}{$10 \times 20$} & $20 \times 20$ \\
\hline Máquina & 3 & 4 & 3 & 4 & 5 & 1 & 5 & 1 \\
\hline Amostra 1 & - & - & - & - & 84 & 34 & 34 & 11 \\
Amostra 2 & - & - & - & - & 58 & 29 & 29 & 15 \\
Amostra 3 & 46 & 46 & - & - & 66 & 26 & 26 & 14 \\
Amostra 4 & 10 & 10 & - & - & 72 & 22 & 22 & 14 \\
\hline
\end{tabular}

Figura 6.4: Resultado da aplicação do algoritmo de Lawler.

Como o programador da produção realiza seu escalonamento mês a mês, procuraremos seguir sua política aplicando o algoritmo de Lawler descrito na 


\begin{tabular}{|l|c|c|c|c|c|c|c|c|}
\hline Tipo & \multicolumn{2}{|c|}{$7,5 \times 7,5$} & \multicolumn{3}{|c|}{$10 \times 10$} & \multicolumn{2}{c|}{$10 \times 20$} & $20 \times 20$ \\
\hline Máquina & 3 & 4 & 3 & 4 & 5 & 1 & 5 & 1 \\
\hline Amostra 1 & - & - & - & - & 84 & 34 & 34 & 11 \\
Amostra 2 & $43^{*}$ & $43^{*}$ & $58^{*}$ & $58^{*}$ & 58 & 29 & 29 & 15 \\
Amostra 3 & 46 & 46 & $66^{*}$ & $66^{*}$ & 66 & 26 & 26 & 14 \\
Amostra 4 & 10 & 10 & - & - & 72 & 22 & 22 & 14 \\
\hline
\end{tabular}

Figura 6.5: Resultados adicionais.

\begin{tabular}{|l|c|c|c|c|c|c|c|c|}
\hline Tipo & \multicolumn{2}{|c|}{$7,5 \times 7,5$} & \multicolumn{3}{|c|}{$10 \times 10$} & \multicolumn{2}{c|}{$10 \times 20$} & $20 \times 20$ \\
\hline Máquina & 3 & 4 & 3 & 4 & 5 & 1 & 5 & 1 \\
\hline Amostra 1 & $(29)$ & $(29)$ & $(29)$ & $(29)$ & 84 & 34 & 34 & 11 \\
Amostra 2 & $43^{*}$ & $43^{*}$ & $58^{*}$ & $58^{*}$ & 58 & 29 & 29 & 15 \\
Amostra 3 & 46 & 46 & $66^{*}$ & $66^{*}$ & 66 & 26 & 26 & 14 \\
Amostra 4 & 10 & 10 & $(29)$ & $(29)$ & 72 & 22 & 22 & 14 \\
\hline
\end{tabular}

Figura 6.6: Número de tarefas das amostras tratadas.

Seção 2.3.4 para as quatro amostras, que correspondem a meses individuais. Na tabela da Figura 6.4 podemos observar o resultado da aplicação deste algoritmo nas amostras. Neste tabela os números correspondem ao número de pedidos para cada amostra utilizada, separados pelos tipos de revestimento e para cada tipo, ainda separados pelas linhas de produção que podem produzi-los. Como já foi descrito anteriormente, esse algoritmo de Lawler é pseudo-polinomial e utiliza uma implementação recursiva. Utilizando tempos "realisticamente" viáveis ${ }^{2}$ conseguimos aplicá-lo com sucesso somente nas amostras que constam nesta tabela. Já para as amostras assinaladas com um traço, dentro do tempo viável que estipulamos em 25 minutos o algoritmo não conseguiu obter a solução ótima.

Uma vez que esbarramos neste problema do tempo de execução para algumas amostras, procuramos examinar mais detalhadamente cada uma delas. Após alguns testes e manipulações, percebemos que se retirássemos de alguns todas as tarefas que possuíam o tempo de conclusão mais longo, obtínhamos um escalonamento sem atraso. Desta forma, como todas as outras tarefas retiradas possuem o mesmo tempo de conclusão, estas poderiam ser conside-

\footnotetext{
${ }^{2}$ Aproximadamente 25 minutos em um microcomputador com processador Pentium II $400 \mathrm{MHz}$, rodando o sistema operacional Windows 98 e com 128 Mbytes de memória RAM.
} 
radas como uma única tarefa e assim conseguimos obter o atraso ótimo dessas amostras. Na tabela da Figura 6.5 podemos observar os resultados obtidos, sendo que esses novos resultados são indicados pelos números assinalados com um asterisco.

Ainda observando a Figura 6.5 notamos que restam algumas amostras sem solução. Como não seria interessante para o trabalho deixar estas amostras sem solução, ou ainda pior, desprezar esses dados experimentais, uma vez que conseguimos obter tão poucos, a solução que adotamos foi reduzir a quantidade de tarefas dessas amostras. Desta forma, decidimos por reduzir o tamanho das amostras para 29 tarefas, que corresponde ao tempo de execução mais próximo do nosso limite aceitável. Na redução do tamanho das amostras tomamos o cuidado de manter a mesma característica da distribuição original das tarefas com relação ao tamanho e tempos de conclusão. E assim, na tabela da Figura 6.6 podemos observar o número de tarefas utilizadas para todas as amostras, sendo que os dados entre parênteses correspondem às amostras reduzidas.

\begin{tabular}{|l|c|c|c|c|c|c|c|c|}
\hline Tipo & \multicolumn{2}{|c|}{$7,5 \times 7,5$} & \multicolumn{3}{|c|}{$10 \times 10$} & \multicolumn{2}{|c|}{$10 \times 20$} & $20 \times 20$ \\
\hline Máquina & 3 & 4 & 3 & 4 & 5 & 1 & 5 & 1 \\
\hline Amostra 1 & 680 & 730 & 8.736 & 14.784 & 0 & 0 & 0 & 0 \\
Amostra 2 & 12.178 & 13.578 & 1.978 & 4.778 & 0 & 0 & 0 & 0 \\
Amostra 3 & 0 & 0 & 11.895 & 14.995 & 0 & 0 & 0 & 0 \\
Amostra 4 & 1.675 & 2.175 & 479 & 2.279 & 0 & 0 & 0 & 0 \\
\hline
\end{tabular}

Figura 6.7: Atraso das amostras tratadas.

A tabela da Figura 6.7 contém os atrasos ótimos obtidos ao se aplicar o algoritmo de Lawler nas amostras da Tabela 6.6. Passaremos agora para a análise desses dados. Observando as amostras do tipo $20 \times 20$ e $10 \times 20$ podemos notar que estas não apresentam nenhum atraso, o mesmo ocorrendo para as amostras do tipo $10 \times 10$ que são processadas na máquina 5 , que é a máquina mais rápida da linha de produção. Dentre esses casos citados acima conseguimos obter um escalonamento ótimo sem atraso utilizando 84 tarefas. Este fato ocorreu pois percebemos que somente ordenando essa amostra pelos tempos de conclusão obtínhamos um escalonamento ótimo sem atraso.

Uma dúvida que pode surgir é que se a união de duas ou mais amostras consecutivas do mesmo tipo não pode também gerar uma outra amostra. $\mathrm{Ou}$ seja, por que não realizar o escalonamento para todos os pedidos que estão 
na carteira no momento. A resposta para essa indagação é não, pois como já foi discutido todos os tempos de conclusão estão separados mensalmente. Dessa forma, como pode ser observado na Tabela 6.7 para as amostras dos tipo $10 \times 20$ e $20 \times 20$ e para o tipo $10 \times 10$ processado na máquina 5 , como todas essas amostras individualmente não possuem atraso, se juntarmos duas ou mais, também permanecerão sem atrasos. Com relação às demais, exceto pelo caso da Amostra 3 do tipo 7,5 $\times 7,5$, que gerou um escalonamento sem atraso, todas as amostras individualmente estão atrasadas. Com isso, somente neste caso poderia gerar alguma diminuição nos atrasos se juntássemos duas amostras. Como a linha de produção da empresa é contínua, essa junção das amostras ocorre naturalmente.

Outro fato é que como durante o período de um mês chegam muitas informações novas na empresa, principalmente provenientes dos clientes, seria mesmo uma boa política para a empresa realizar o escalonamento novamente no início de todo mês. Note que para a linha de produção da empresa este é um período relativamente longo de planejamento. Desta forma a empresa teria nas mãos mais uma ferramenta para rever possíveis mudanças nos tempos de conclusão, rodando novamente os escalonamentos do próximo mês.

\subsection{Resolvendo o problema $4 Q|| \Sigma T_{j}$}

O problema real que temos de resolver se caracteriza por quatro máquinas uniformes $(Q)$, com velocidades de processamento diferentes para tipos distintos de tarefas. E ainda, cada máquina somente produz alguns dos tipos de tarefas, não existindo nenhuma máquina na linha de produção que possa produzir todos os tipos. Desta forma, levando em conta os resultados contidos na tabela da Figura 6.7, proporemos uma heurística que envolva as quatro máquinas conjuntamente, baseada nos resultados obtidos para cada máquina individualmente.

O primeiro passo é atribuir à máquina 1 a execução dos pedidos do tipo $20 \times 20$. Essa escolha é óbvia pois a máquina 1 é a única que pode produzir esse tipo de tarefa. Atribuindo a máquina 1 ao tipo $20 \times 20$, nos resta atribuir o tipo $10 \times 20$ à máquina 5 . Feito isso, precisamos determinar quais tipos as máquinas 3 e 4 produzirão.

Como o máquina 3 possui uma velocidade de produção um pouco maior do que a máquina 4 e os atrasos obtidos para o tipo $10 \times 10$ são maiores do que aqueles obtidos para o tipo $7,5 \times 7,5$ (ambas produzem os dois tipos), 
escalonaremos o tipo $10 \times 10$ para a máquina 3 e o tipo $7,5 \times 7,5$ para a máquina 4. A tabela da Figura 6.8 resume essa heurística.

\begin{tabular}{|l|c|c|c|c|}
\hline Tipo & $7,5 \times 7,5$ & $10 \times 10$ & $10 \times 20$ & $20 \times 20$ \\
\hline Máquina & 4 & 3 & 5 & 1 \\
\hline
\end{tabular}

Figura 6.8: Atribuição inicial para a solução do problema completo.

Podemos refinar essa solução, uma vez que se a seguirmos à risca, as máquinas 1 e 5 ficariam ociosas, enquanto que as máquinas 3 e 4 provavelmente estariam produzindo tarefas atrasadas, principalmente se levarmos em conta que nos dados da Figura 6.7 constam atrasos para amostras com o conjunto de tarefas reduzido.

A idéia da estratégia refinada é a seguinte: depois que a máquina 1 terminar o processamento das tarefas do mês corrente, até o final desse mesmo mês ela vai processar as tarefas do mês do tipo 10 × 20 que ainda não foram processadas pela máquina 5. A partir desse momento a máquina 5 (que é a máquina mais rápida de toda a linha de produção) passa a produzir as tarefas do mês do tipo $10 \times 10$ que ainda não foram processadas pela máquina 3 . E por fim a máquina 3 passa a dividir com a máquina 4 a produção das tarefas do mês que ainda restam do tipo $7,5 \times 7, \overline{5}$. Nessa heurística a máquina 4 sempre produz tarefas do tipo $7,5 \times 7,5$.

Neste refinamento reunimos todas as máquinas para um escalonamento mês a mês. Ou seja, se uma máquina terminou de processar suas tarefas com data de entrega para aquele mês, ela passa a "ajudar" outra máquina. Naturalmente teremos de considerar o tempo de ajuste quando a máquina passa a produzir outro tipo de tarefa. Na tabela da Figura 6.9 resumimos essa heurística refinada.

\begin{tabular}{|l|c|c|c|c|}
\hline Máquina & 1 & 3 & 4 & 5 \\
\hline Fase 1 & $20 \times 20$ & $10 \times 10$ & $7,5 \times 7,5$ & $10 \times 20$ \\
Fase 2 & $10 \times 20$ & $7,5 \times 7,5$ & $7,5 \times 7,5$ & $10 \times 10$ \\
\hline
\end{tabular}

Figura 6.9: Heurística refinada.

A Fase 1 corresponde à primeira parte da heurística. A Fase 2 inicia quando a máquina 1 termina de processar os pedidos do tipo $20 \times 20$ (lembramos que esse tipo é o que contém as menores quantidades a serem processadas). 
Deste ponto em diante, até o final do mês corrente, as máquinas serão atribuídas aos tipos relacionados na Fase 2. No início de cada mês as atribuições retornam àquelas da Fase 1.

Decidimos por propôr essa heurística que escalona as tarefas mês a mês a fim de permitir ao programador da produção reavaliar suas decisões no início de cada mês. Essa liberdade é importante pois durante um mês surgem muitas informações, como por exemplo: novos pedidos urgentes, pedidos de clientes importantes, máquinas que se quebram, etc. Desta forma o programador tem a possibilidade de reavaliar seu escalonamento todo mês, levando em consideração as novas informações disponíveis.

\begin{tabular}{|c|c|c|c|c|c|}
\hline \multicolumn{2}{|c|}{} & $7,5 \times 7,5$ & $10 \times 10$ & $10 \times 20$ & $20 \times 20$ \\
\hline \multirow{4}{*}{ Amostra } & Fase 1 & 730 & 0 & 0 & 0 \\
\cline { 2 - 6 } & Fase 2 & 0 & 0 & 0 & - \\
\cline { 2 - 6 } & Atraso Total & 730 & 0 & 0 & 0 \\
\hline \multirow{4}{*}{ Amostra 2 } & Fase 1 & 0 & 0 & 0 & 0 \\
\cline { 2 - 6 } & Fase 2 & 2840 & 0 & 0 & - \\
\cline { 2 - 6 } & Atraso Total & 2840 & 0 & 0 & 0 \\
\hline \multirow{3}{*}{ Amostra 3 3} & Fase 1 & 0 & 0 & 0 & 0 \\
\cline { 2 - 6 } & Fase 2 & 0 & 0 & 0 & - \\
\cline { 2 - 6 } & Atraso Total & 0 & 0 & 0 & 0 \\
\cline { 2 - 6 } & Fase 1 & 2175 & 479 & 0 & 0 \\
\cline { 2 - 6 } & Fase 2 & 0 & 0 & 0 & - \\
\cline { 2 - 6 } & Atraso Total & $\mathbf{2 1 7 5}$ & 479 & 0 & 0 \\
\hline
\end{tabular}

Figura 6.10: Resultados da heurística refinada.

$\mathrm{Na}$ tabela da Figura 6.10 podemos observar os resultados obtidos pela aplicação da heurística refinada. Esta tabela contém os atrasos por amostra e para cada amostra separados por tipo e fase, além de mostrar os respectivos atrasos totais. Analisando esses dados podemos notar que a heurística refinada gerou bons resultados. Por exemplo, para os pedidos do tipo $10 \mathrm{x}$ 20 e $20 \times 20$, não obtivemos atrasos. Para o tipo $10 \times 10$, obtivemos algum atraso somente para a Amostra 4, enquanto que para o tipo $7,5 \times 7,5$ os atrasos obtidos foram compatíveis com aqueles listados na Figura 6.7. 


\section{Considerações Finais}

A primeira consideração que fazemos é que conseguimos atingir o objetivo principal deste trabalho. Ou seja, depois de percorrermos todo o processo de pesquisa de campo, revisão teórica e a modelagem, construímos uma solução para o problema da empresa. Talvez esta seja a principal contribuição deste trabalho, ou seja, deixar descrito todos os passos necessários para a realização de um estudo de caso real, envolvendo pesquisa de campo.

Toda a revisão teórica é realizada na primeira parte do trabalho. Esta revisão consiste da descrição de alguns dos principais resultados encontrados na literatura tanto para uma como para várias máquinas paralelas. Para alguns problemas descrevemos também os algoritmos ou heurísticas relacionados.

A segunda parte do trabalho é reservada para o estudo de caso propriamente dito. Iniciamos com a descrição de todo o processo produtivo da empresa. A seguir analisamos o problema e chegamos a uma versão simplificada do mesmo, que foi modelada utilizando programação linear inteira (PLI). Como os resultados utilizando PLI não foram muito animadores com relação aos tempos de execução, construímos uma heurística para o problema baseada em um algoritmo ótimo relacionado encontrado na literatura.

Gostaríamos de enfatizar que a avaliação desta solução somente pôde ser realizada em função dos dados experimentais disponíveis, que na verdade eram bastante restritos. Outro fato que gostaríamos de destacar é que durante a execução deste trabalho sempre nos preocupamos em obter uma solução que fosse viável para a empresa. Por viabilidade pode-se entender uma solução com baixo custo e que não exige conhecimentos específicos por parte do programador da produção. Sem dúvida essas são questões que pesam bastante para a direção de uma empresa.

Finalmente, um ponto que ficou faltando para a perfeita conclusão deste trabalho seria a aplicação desta solução diretamente na empresa, através de sua utilização no dia a dia pelo programador da produção. Infelizmente isto 
não foi possível.

Algumas possíveis extensões deste trabalho poderiam ser realizadas futuramente com o intuito de enriquecê-lo. Por exemplo, como o problema possui somente dois tempos de chegada distintos, seria interessante tentar encontrar um algoritmo que utilizasse especificamente esta informação, ao invés de tratar os tempos de chegada genéricos. $\mathrm{O}$ mesmo ocorre na procura de um algoritmo para máquinas paralelas que fosse específico para quatro máquinas; e também um algoritmo que envolvesse somente quatro tipos de tarefas. Certamente alguns desses temas podem produzir trabalho futuros interessantes. 


\section{Glossário de termos}

$C_{j} \quad$ Tempo de finalização (completion time) da tarefa $j$

$C_{\max } \quad$ Makespan

$d_{j} \quad$ Tempo de conclusão (due date) da tarefa $j$

$E D D$ Seqüenciamento pelo tempo de conclusão mais próximo (Earliest Due Date)

$E_{j} \quad$ Adiantamento corrigido (earliness) da tarefa $j$

$\bar{F} \quad$ Tempo de execução médio

$F_{j} \quad$ Tempo de execução (flowtime) da tarefa $j$

$F_{\max } \quad$ Tempo de execução máximo

$\bar{J} \quad$ Número médio de tarefas no sistema durante um intervalo de tempo

$J(t) \quad$ Número de tarefas no sistema no tempo $t$

$L_{\max } \quad$ Atraso máximo

$L_{j} \quad$ Atraso (lateness) da tarefa $j$

$L P T$ Seqüenciamento pelo maior tempo de processamento

(Longest Processing Time)

$m \quad$ Número de máquinas

$n \quad$ Número de tarefas

$N_{T} \quad$ Número de tarefas atrasadas

$P \quad$ Máquinas paralelas idênticas

$p_{j} \quad$ Tempo de processamento (processing time) da tarefa $j$

pmtn Interrupção permitida (preemption)

prec Precedência

$Q \quad$ Máquinas paralelas uniformes

$R \quad$ Máquinas paralelas não relacionadas

$r_{j} \quad$ Tempo de chegada (release time) da tarefa $j$

SPT Seqüenciamento pelo menor tempo de processamento (Shortest Processing Time)

SRPT Seqüenciamento pelo menor tempo de processamento restante 
(Shortest Remaining Processing Time)

$t_{j} \quad$ Tempo de início da tarefa $j$

$\bar{T} \quad$ Atraso corrigido médio

$T_{j} \quad$ Atraso corrigido (tardiness) da tarefa $j$

$T_{\max } \quad$ Atraso corrigido máximo

$U_{j} \quad$ Penalidade unitária da tarefa $j$

$w_{j} \quad$ Peso ou prioridade da tarefa $j$

WSPT Seqüenciamento pelo menor tempo de processamento ponderado (Weighted Shortest Processing Time)

$Z_{0}^{+} \quad$ Conjunto dos números inteiros positivos 


\section{Referências Bibliográficas}

[Bak74] K. R. Baker. Introduction to sequencing and scheduling. New York, Wiley, 1974.

[BCS74] J. L. Bruno, E. G. Coffman, and R. Sethi. Scheduling independent tasks to reduce mean finishing time. Comm. ACM, 17:382-387, 1974.

[BLLK83] K. R. Baker, E. L. Lawler, J. K. Lenstra, and A. H. G. Rinnooy Kan. Preemptive scheduling of a single machine to minimize maximum cost subject to release states and precedence constraints. Operations Research, 26:111-120, 1983.

[BM73] K. R. Baker and A. G. Merten. Scheduling with parallel processors and linear delay costs. Naval Research Logistcs Quaterly, 20(4), December 1973.

[Bru98] P. Brucker. Scheduling algorithms. Springer, 2 edition, 1998.

[CG72] E. G. Coffman and R. L. Graham. Optimal scheduling for two processor systems. Acta Informatica, 1:200-213, 1972.

[CMM67] R. W. Conway, W. L. Maxwell, and L. W. Miller. Theory of Scheduling. Addison-Wesley, Reading, MA, 1967.

[DJ81] E. Davis and J. M. Jaffe. Algorithms for scheduling tasks on unrelated processors. J. Assoc. Comput. Mach., 28:721-736, 1981.

[DL90] J. Du and J. Y. T. Leung. Minimizing total tardiness on one machine is $\mathcal{N} \mathcal{P}$-hard. Mathematics of Operations Research, 15:483495, 1990 . 
[DL91] J. Du and J. Y. T. Leung. Minimizing the number of late jobs on unrelated machines. Operation Research Letters, 10:153-158, 1991.

[DLLdV90] M. I. Dessouky, B. J. Lageweg, J. K. Lenstra, and S. L. Van de Velde. Scheduling identical jobs on uniform parallel machines. Statistica Neerlandica, 44:115-123, 1990.

[DLW92] J. Du, J. Y. T. Leung, and C. S. Wong. Minimizing the number of late jobs with release time constraints. J. Combin. Math. Combin. Comput., 11:97-107, 1992.

[DLY90] J. Du, J. Y. T. Leung, and G. H. Young. Minimizing mean flow time with release time constraint. Theoretical Computer Science, 75:347-355, 1990.

[EEI64] W. L. Eastman, S. Even, and I. M. Isaacs. Bounds for the optimal scheduling of $n$ jobs on $m$ processors. Management Science, 11(2), November 1964.

[FG86] A. Federgruen and G. Groenevelt. Preemptive scheduling of uniform machines by ordinary network flow techniques. Management Science, 32:341-349, 1986.

[Fre83] G. N. Frederickson. Scheduling unit-time tasks with integer release times and deadlines. Inform. Process. Lett., 16:171-173, 1983.

[GJ76] M. R. Garey and D. S. Johnson. Scheduling tasks with nonuniform deadlines on two processors. Jornal of the ACM, 23:461467, 1976.

[GJ77] M. R. Garey and D. S. Johnson. Two-processor scheduling with start-time and deadlines. SIAM J. Comput., 6:416-426, 1977.

[GJ78] M. R. Garey and D. S. Johnson. Strong $\mathcal{N} \mathcal{P}$-completeness results: motivation, examples and implications. J. Assoc. Comput. Mach., 25:499-508, 1978.

[GJ79] M. R. Garey and D. S. Johnson. Computers and intractability: a guide to the theory of NP-Completeness. Freeman, San Francisco, 1979. 
[GLLK79] R. L. Graham, E. L. Lawler, J. K. Lenstra, and A. H. G. Rinnooy Kan. Optimization and approximation in deterministic sequencing and scheduling: a survey. Ann. Discrete Math., 4:287-326, 1979.

[Gra66] R. L. Graham. Bounds for certain multiprocessing anomalies. Bell System Technical Journal, 45:1563-1581, 1966.

[Gra69] R. L. Graham. Bounds on multiprocessing timing anomalies. SIAM J. Appl. Math., 17:416-426, 1969.

[HL90] L. A. Heerbach and J. Y. T. Leung. Preemptive scheduling of equal length jobs on two machines to minimize mean flow time. Operations Research, 38:487-494, 1990.

[Hor74] W. A. Horn. Some simple scheduling algorithms. Naval Res. Logist Quart., 21:177-185, 1974.

[HS76] E. Horowitz and S. Sahni. Exact and approximate algorithms for scheduling nonidentical processors. J. Assoc. Comput. Mach., 23:317-327, 1976.

[HS87] D. S. Hochbaum and D. B. Shmoys. Using dual approximation algorithms for scheduling problems: theoretical and pratical result. J. ACM, 34:144-162, 1987.

[HS89] L. A. Hall and D. B. Shmoys. Approximation schemes for constrained scheduling problems. In Proceedings of the 30th Annual Symposium on Foundations of Computer Science, pages 134140, 1989.

[HS92] L. A. Hall and D. B. Shmoys. Jackson's rule for single-machine scheduling: making a good heuristic better. Math. Oper. Res., 17:22-35, 1992.

[Hu61] T. C. Hu. Parallel sequencing and assembly line problems. Operations Research, 9(6), November 1961.

[Jac55] J. R. Jackson. Scheduling a production line to minimize maximum tardiness. Technical Report 43, Mgmt. Sci. Research Project, UCLA, 1955. 
[Kar72] R. M. Karp. Reducibility among combinatorial problems. In R. E. Miller and J. W. Thatcher, editors, Complexity of Computer Computations, pages 85-103. Plenum Press, New York, 1972.

[Ked70] S. K. Kedia. A job shop scheduling problem with parallel machines. Unpublished report, Department of Industrial Engineering, University of Michigan, 1970.

[KLL75] A. H. G. Rinnooy Kan, B. J. Lageweg, and J. K. Lenstra. Minimizing total costs in one-machine scheduling. Operations Research, 23:908-927, 1975.

[Law73] E. L. Lawler. Optimal sequencing of a single machine subject to precedence constraints. Management Sci., 19:544-546, 1973.

[Law77] E. L. Lawler. A "pseudopolynomial" algorithm for sequencing jobs to minimize total tardiness. Annals of Discrete Mathematics, 1:331-342, 1977.

[Law79] E. L. Lawler. Preemptive scheduling of uniform parallel machines to minimize the weighted number of late jobs. Technical report, Centre for Mathematics and Computer Science, Amsterdan, 1979. Report BW 105.

[Law82] E. L. Lawler. Preemptive scheduling of precedence-constrained jobs on parallel machines. In Dempster et al., editor, Deterministic and Stochastic Scheduling, pages 101 123. Reidel, Dordrecht, 1982.

[Law83] E. L. Lawler. Recent results in the theory of machine scheduling. In A. Bachem, M. Grötschel, and B. Korte, editors, Mathematical Programming: the state of Art - Bonn 1982, pages 202-234. Springer, Berlin, 1983.

[Law90] E. L. Lawler. A dynamic programming algorithm for preemptive scheduling of a single machine to minimize the number of late jobs. Annals of Operations Research, 26:125-133, 1990. 
[LK78] J. K. Lenstra and A. H. G. Rinnooy Kan. Complexity of scheduling under precedence constraints. Operations Research, 26:2235,1978 .

[LKB77] J. K. Lenstra, A. H. G. Rinnooy Kan, and P. Brucker. Complexity of machine scheduling problems. Annals of Discrete Mathematics, 1:343-362, 1977.

[LL78] E. L. Lawler and J. Labetoulle. On preemptive scheduling on unrelated parallel processors by linear programming. J. Assoc. Comput. Mach., 25:612-619, 1978.

[LLKS93] E. L. Lawler, J. K. Lenstra, A. H. G. Rinnooy Kan, and D. B. Shmoys. Sequencing and scheduling: algorithms and complexity. In S. C. Graves, A. H. G. Rinnooy Kan, and P. Zipkin, editors, Handbooks in Operations Research and Management Science, volume 4 of Logistic of Production and Inventory, pages 445-522. North-Holland, 1993.

[LLLK84] J. Labetoulle, E. L. Lawler, J. K. Lenstra, and A. H. G. Rinnooy Kan. Preemptive scheduling of uniform machines subject to release dates. In H. R. Pulleyblank, editor, Progress in Combinatorial Optimization, pages 245-261. Academic Press, New York, 1984.

[LM69] E. L. Lawler and J. M. Moore. A functional equation and its application to resource allocation and sequencing problems. $\mathrm{Ma}$ nagement Science, 16:77-84, 1969.

[LST90] J. K. Lenstra, D. B. Shmoys, and E. Tardos. Approximation algorithms for scheduling unrelated parallel machines. Math. Programming, 46:259-271, 1990.

[LY90] J. Y. T. Leung and G. H. Young. Preemptive scheduling to minimize mean weighted flow time. Information Processing Letters, 34:47-50, 1990 .

[Max70] W. L. Maxwell. On the generality of the equation $l=\lambda w$. Operations Research, 18(1), 1970. 